American Journal of Infectious Diseases 1 (2): 90-106, 2005

ISSN 1553-6203

(C) 2006 Science Publications

\title{
Induction of Caspase-dependant Apoptosis by Enterovirus 70 in Human Lens Epithelial SRA01/04 Cells
}

\author{
${ }^{1}$ Dequan Chen, ${ }^{1}$ Chris Duggan, ${ }^{1}$ Donald E. Texada, ${ }^{1}$ Youping Deng \\ ${ }^{2}$ Chanping Liang, ${ }^{1}$ Thomas B. Reden and ${ }^{1}$ Marlyn P. Langford \\ ${ }^{1}$ Department of Ophthalmology, Louisiana State University Health Sciences Center \\ Shreveport, LA 71130, USA \\ ${ }^{2}$ Department of Biology, The University of Southern Mississippi, Hattiesburg, MS 39401, USA
}

\begin{abstract}
Enterovirus 70 (EV70), an etiological agent of acute hemorrhagic conjunctivitis (AHC), induces apoptosis in human Chang's conjunctival (HCC) cells. EV70 is also able to infect and replicate in some other human cells such as human lens epithelial SRA01/04 cells and U937 cells. EV70 infection was found to induce apoptosis in SRA01/04 cells. During EV70-induced apoptosis of SRA01/04 cells, the expression levels of procaspase-3, 6 and 7 (all 32kD) were not increased, but procaspase- 3 and 7 were activated (cleaved) while the constitutively activated caspase-6 decreased. Z-VD-FMK inhibited EV70-induced apoptosis and extracellular EV70 release, but not intracellular viral production. UV- or heat-inactivated EV70 did not induce apoptosis. Guanidine $\mathrm{HCl}$ inhibited EV70 induced apoptosis in a multiple-step viral growth experiment but not in a one-step viral growth experiment. Cycloheximide and high concentration of methoxysuccinyl-Ala-Ala-Pro-Val-chloromethylketone (MPCMK) $(0.5 \mathrm{mM})$ or elastatinal (Ela) $(125 \mathrm{mM})$ also inhibited EV70-induced apoptosis. The results suggest that infectious EV70 is capable of inducing caspase-dependent (especially caspases-3 and 7-dependent) apoptosis in human lens SRA01/04 cells that requires the syntheses of viral proteins, but not viral genome RNA. The results suggest that (a) EV70 protease(s) (2A protease and probably $3 \mathrm{C}$ protease) produced during viral replication initiates EV70 induced apoptosis of SRA01/04 cells and (b) EV70 may use similar or same mechanism(s) to induce apoptosis in different human cells such as SRA01/04 and HCC cells.
\end{abstract}

Key words: Enterovirus 70, apoptotic DNA ladder, APOPercentage dye uptake bioassay, effector caspase, caspase-3, caspase-6, caspase-7, caspase inhibitor IX, 2A protease, 3C protease

\section{INTRODUCTION}

EV70 and coxsackievirus 24 variant $(\mathrm{CA} 24 \mathrm{v})$ are the etiological agents of acute hemorrhagic conjunctivitis (AHC), a highly contagious ocular disease that can affect individuals of all ages and both sexes ${ }^{[1,2]}$. EV70 has so far been reported to cause two pandemics, many recurrent epidemics and sporadic cases of AHC, especially in many tropical countries ${ }^{[3]}$. EV70 can also cause neurological complications $(1: 10,000)$ including asymmetrical flaccid motor paralysis (radiculomyelitis) similar to poliomyelitis and cranial nerve palsies as well as a dysautonomic feature ${ }^{[4-8]}$.

Natural and experimental EV70 infection is generally localized to the superficial conjunctival epithelial cell layer (i.e., conjunctivitis) and corneal epithelium (i.e., keratitis) ${ }^{[9,10]}$ and results in AHC. Although it cannot infect and replicate in all kinds of human cells, EV70 has been found to be able to infect and replicate in a broad range of human cells including leukocyte cells (A2.01, Daudi, HL60, Jurkat, Raji, THP-1 and U937 $)^{[11]}$ and human eye cells such as HCC cell $^{[12]}$, SRA01/04 cells ${ }^{[13]}$, human retina and retina pigment epithelial cells (unpublished). Therefore, EV70 may potentially cause human diseases other than AHC and its neurological complications.

In EV70 caused AHC (EV70 AHC), viral infection can cause lysis of conjunctival and corneal epithelial cells $^{[14]}$, most likely through virus-induced epithelial cell death in conjunctiva and cornea ${ }^{[15]}$. Previously, we have reported that EV70 induced apoptosis at body temperature $\left(37^{\circ} \mathrm{C}\right)$ is an important mechanism for EV70 $\mathrm{AHC}^{[12]}$. At body temperature, whether EV70 infection can cause apoptosis in other permissive human cells and whether EV70 uses the same or different mechanism(s) to induce apoptosis in different human cells, have not yet been determined. In the present study, we demonstrate that EV70 infection also induced caspase-dependent apoptosis in SRA01/04 cells by a mechanism similar to the one for EV70 induced apoptosis in HCC cells although there exist some differences in the virus induced apoptosis in both cells.

\section{MATERIALS AND METHODS}

Cells, EV70 J670/71 and EV70 hyperimmune antiserum: Human lung fibroblast cells (Wi38) were purchased from ATCC (American Type Culture 
Collection, Manassas, VA). Human lens epithelial cells (SRA01/04) were a gift from Dr. Venkat N. Reddy (Department of Ophthalmology and Visual Sciences, Kellogg Eye Center, Uni. MI, Ann Arbor, MI). Cells were maintained in Dulbecco's minimum essential medium (DMEM) supplemented with $10 \%$ bovine calf serum (BCS) and $1 \times$ antibiotic and antimycotic solution (Sigma, St. Louis, MO). For experiments, cell suspensions in culture medium were pipetted into 6well culture dishes $\left(1 \times 10^{6}\right.$ cells $\left./ \mathrm{ml}\right)$ and incubated at $37^{\circ} \mathrm{C}$ in a humidified $5 \% \mathrm{CO}_{2}$ atmosphere ${ }^{[16]}$. EV70 epidemic isolate (J670/71, EV70 standard strain) from Japan was generously provided by Dr. Marguerite YinMurphy (Department of Microbiology, National University of Singapore, Singapore). Stocks of EV70 were grown in human Wi38 cells, aliquoted and stored at $-100^{\circ} \mathrm{C}$. Analysis of EV70 induced apoptosis was performed in SRA01/04 cells. The preparation of EV70 J670/71-specific hyperimmune rabbit antiserum was made using UV-inactivated EV70 whole-virus ${ }^{[13]}$.

Infection of SRA01/04 cells by EV70 with or without inhibitors: SRA01/04 cells on 6-well or 96-well plates were inoculated with EV70 J670/71 at m.o.i.s ranging from $2 \times 10^{-6}$ to $50 \mathrm{PFU} /$ cell. After allowing $1 \mathrm{~h}$ for absorption, the inoculum was removed and incubated at $37^{\circ} \mathrm{C}$ in fresh DMEM with $2 \%$ BCS. At the indicated times post infection (p.i.), infected cells or culture media were harvested for intra- and/or extracellular virus titer analysis (virus quantitation), DNA ladder analysis, quantitation of apoptosis by APOPercentage dye uptake bioassay, effector caspase-3, 6 or 7 enzyme activity analysis and Western blot analysis of EV70 major capsid proteins (VP1, VP2 or VP3) or effector caspase-3, 6 or 7 . In addition to infection with native infectious EV70 (wt EV70), SRA01/04 cells were also infected at the same nominal m.o.i. with UV-inactivated EV70 (UV-EV70) or heat-inactivated EV70 ( $\triangle$ EV70). The UV-EV70 was prepared by exposing EV70 (3 ml of EV70 suspension in a 100 -mm tissue culture dish) to $250 \mathrm{~mJ}$ UV light. The $\Delta \mathrm{EV70}$ was prepared by incubation of EV70 at $56^{\circ} \mathrm{C}$ or $65^{\circ} \mathrm{C}$ for half an hour. In the experiments with guanidine $\cdot \mathrm{HCl}$ (Gua), cycloheximide (CHX), elastatinal (Ela) and methoxysuccinyl-Ala-Ala-Pro-Val-chloromethylketone (MPCMK) (Sigma, St. Louis, MO), the chemicals (inhibitors) were added at the indicated final concentrations to SRA01/04 cultures $1 \mathrm{~h}$ prior to EV70 infection and were continuously present throughout the indicated entire culture periods. In the case of cultures containing caspase inhibitor IX (Z-VD-FMK) (Calbiochem, San Diego, CA), 0.2, 1.0, 5, or $25 \mu \mathrm{M}$ (final concentrations) was added at $0 \mathrm{~h}$ post EV70 infection or $10 \mu \mathrm{M}$ (final concentration) at $0 \mathrm{~h}-7 \mathrm{~h}$ post EV70 infection and was continuously present throughout the indicated entire periods.

Virus quantitation: Mock- and virus-infected SRA01/04 cells in 6-well plates (infected with $2 \times 10^{6}$ pfu of infectious EV70 J670/71) were harvested and lysed in $200 \mu \mathrm{l}$ of PBS with 3 cycles of freeze-andthaw. The cell lysates were then centrifuged at $15,000 \times$ $\mathrm{g}$ for $5 \mathrm{~min}$ to recover the supernatants (intracellular virus samples). Media from the above mock- and virusinfected SRA01/04 cells were also collected ( $1 \mathrm{ml} /$ well) and centrifuged at $15,000 \times \mathrm{g}$ for $5 \mathrm{~min}$ to recover the supernatants (extracellular virus samples). The total number of infectious virus (plaque forming units, PFU) in each virus stock and sample (extracellular or intracellular virus sample) was determined in human lens epithelial cells (SRA01/04) maintained as previously described ${ }^{[17]}$. Briefly, virus stocks were diluted (10-fold dilution series) in DMEM supplemented with bovine calf serum (2\% v/v) and 100 $\mu \mathrm{l}$ of each virus dilution added to triplicate cultures of confluent SRA01/04 in 96-well tissue culture plates (Sarstedt, Inc., Newton, NC). After $1 \mathrm{~h}$ of incubation at $37{ }^{\circ} \mathrm{C}$, the culture medium was removed, rinsed twice with PBS (0.1 ml/culture well) and fresh DMEM pipetted onto the monolayers of SRA01/04 cells. After visible plaques appeared at 24-36 h of incubation at 37 ${ }^{\circ} \mathrm{C}$, the culture plates were stained and fixed with $0.1 \%$ crystal violet and $20 \%$ methanol. The excess dye was removed from the cultures by rinsing 3 times in tap water and the number of infectious virus $/ \mathrm{ml}$ was calculated by plaque counts as previously described ${ }^{[18]}$.

DNA ladder analysis for apoptotic cells: Apoptotic DNA ladders were identified as previously described $^{[19,20]}$. Briefly, $0.4 \mathrm{ml}$ of cell lysis buffer (50 $\mathrm{mM}$ Tris $\cdot \mathrm{Cl}, 10 \mathrm{mM}$ EDTA, $0.5 \%$ Triton $\mathrm{X}-100,0.5 \%$ $\mathrm{NP}-40, \mathrm{pH} 7.6$ ) was added to cells in 6-well culture plate cultures and stored at $-70^{\circ} \mathrm{C}$. The cell lysate was phenol extracted and nucleic acids were precipitated by ethanol and recovered by centrifugation at $12,000 \times \mathrm{g}$. The pellets were sequentially washed with $70 \%$ and $100 \%$ ethanol and then air-dried for $5 \mathrm{~min}$. The nucleic acid fraction was dissolved in RNase A digestion buffer (50 mM Tris. Cl, $5 \mathrm{mM}$ EDTA, $60 \mu \mathrm{g} / \mathrm{ml}$ RNase A, pH 7.5) and samples were incubated at $37^{\circ} \mathrm{C}$ for $60 \mathrm{~min}$ to allow complete RNA digestion before running them on $1.2 \%$ agarose gel. DNA bands were visualized with ethidium bromide under ultraviolet light and digital images were obtained using a Bio-Rad Gel Documentation System with Quantity One software.

APOPercentage dye uptake bioassay: Apoptosis levels of SRA01/04 cells induced by mock- or EV70 infection on 96-well plates were determined using APOPercentage Apoptosis Assay kit (Biocolor Ltd., Newtonabbey, Northern Ireland) according to the manufacturer's instructions with the following modification. Briefly, APOPercentage dye ( $5 \mu 1$ of dye in $20 \mu \mathrm{l}$ of DMEM/well) was added to mock- or EV70 J670/71-infected confluent SRA01/04 cell cultures (covered with $100 \mu \mathrm{l}$ of DMEM /well) $45 \mathrm{~min}$ prior to 
the end of each infection. Culture media with the dye and detached cells were removed and centrifuged at $15,000 \times \mathrm{g}$ for $5 \mathrm{~min}$ and washed 2 times with PBS. Cells still adherent to the 96-well plates were also washed 2 times with PBS and photographed to document dye uptake of individual apoptotic cells. For colorimetric quantitation of apoptosis levels, the washed pellet from the culture medium of each well were suspended in $100 \mu 1$ of the Dye Release Reagent in the kit and transferred back to the original well of the 96-well plates. The APOPercentage dye accumulated in SRA01/04 cells and/or apoptotic bodies was then released by gently shaking the 96 -well plates at room temperature for $10 \mathrm{~min}$. The released dye solutions from every 2 wells were pooled and the amount was quantitated by measuring OD570 (three parallel experiments were performed for the quantitation).

Western-blot analysis: Mock- or virus-infected SRA01/04 cells from 6-well plates were lysed by boiling in $1 \times$ cell-lysis buffer $(50 \mathrm{mM}$ Tris. $\mathrm{Cl}, 150 \mathrm{mM}$ $\mathrm{NaCl}, 1.5 \mathrm{M}$ Urea, 2\% SDS, $8 \%$ glycerol) for $5 \mathrm{~min}$. Total proteins in the above whole-cell lysates were determined by Dc Protein Assay Kit (Bio-Rad, Hercules, CA) as per the manufacturer's instruction. The whole-cell lysates were adjusted to the same protein concentration $(3 \mu \mathrm{g} / \mu \mathrm{l})$ by $1 \times$ cell-lysis buffer and final concentrations of $100 \mathrm{mM}$ DTT and $0.02 \%$ bromophenol blue were added to each sample. The whole-cell lysate protein samples were separated on $10 \%$ SDS polyacrylamide gel $(\mathrm{C}=4 \%)$ and then transblotted onto nitrocellulose membranes (Pierce Biotechnology, Inc., Rockford, IL). Blots were probed by antibodies to human caspase-3, casepase- 6 or caspase-7 (Cell Signaling Technology, Inc., Beverly, MA) or antibodies to EV70 J670/71 (EV70 J670/71 hyperimmune antiserum) and subsequently the corresponding horseradish peroxidase (HRP) conjugated secondary goat anti-rabbit $\operatorname{IgG}\left(\mathrm{F}\left(\mathrm{ab}^{\prime}\right)_{2}\right.$ fragment specific) (Jackson ImmuniResearch Laboratories, Inc., West Grove, PA). Metal enhanced DAB substrate kit (Pierce Biotechnology, Inc., Rockford, IL) was used to visualize the positive protein bands. Digital images and the relative amounts of $\beta$ actin, procaspases-3, 6 and 7 (all $32 \mathrm{kD}$ ) as well as activated caspases-3 (14 kD), 6 (26 kD) and 7 (26 kD) were obtained using a HP ScanJet 6300C and the ImageJ software ${ }^{[21]}$.

Measurements of enzymatic activities of effector caspases: Mock- or EV70 infected SRA01/04 cells were lysed in $1 \times$ cell lysis buffer (50 mM HEPES, 10 mM CHAPS, $5 \mathrm{mM}$ DTT, $\mathrm{pH}$ 7.4) on ice for $20 \mathrm{~min}$ and centrifuged at $15,000 \times \mathrm{g}$ at $4^{\circ} \mathrm{C}$ for $10 \mathrm{~min}$ to recover the supernatants (cell extracts). The protein amounts in the cell extracts were measured by Dc Protein Assay Kit (Bio-Rad, Hercules, CA) and adjusted to the same concentrations $(1.5 \mu \mathrm{g} / \mu \mathrm{l})$ by the above $1 \times$ cell lysis buffer. Caspase-3-like activity in the cell extracts was determined by colorimetric caspase-3 assay kit (CASP-3-C, Sigma, St. Louis, MO) according to the manufacturer's instruction. Caspase-6 activity in the cell extracts was determined by substrate Ac-VEID-pNA with other components in the above caspase-3 assay kit. Caspase-7 activity in the cell extracts was determined by the following method: 100 $\mu \mathrm{l}(150 \mu \mathrm{g})$ of the cell extracts $(\mathrm{NaCl}$ was added to the final concentration of $150 \mathrm{mM}$ ) were first immunoprecipitated overnight by antibody to human caspase-7 (1:50) and $15 \mu \mathrm{l}$ of rProtein $\mathrm{G}$ agarose (Exalpha Biologicals, Inc., Maynard, MA) at $4^{\circ} \mathrm{C}$. The agarose-rProtein $\mathrm{G}$ bound antibody-Caspase-7 complex was then washed 3 times with the above $1 \times$ cell lysis buffer and the caspase-7 activity was measured by the above colorimetric caspase-3 assay kit (Sigma) as per the manufacturer's instruction. In the present study, one unit of caspase-3, caspase-6 or caspase-7 was defined as 1 nanomole of pNA released per hour per $\mathrm{ml}$ of cell extract at $37^{\circ} \mathrm{C}$.

\section{RESULTS}

EV70 induces apoptosis of SRA01/04 cells in a doseand time-dependent manner: To determine whether EV70 infection is capable of inducing apoptosis of human lens epithelial cells, SRA01/04 cells were cultured in 6-well plates and infected with EV70 $\mathrm{J} 670 / 71$ at various multiplicity of infection (m.o.i.) at $37^{\circ} \mathrm{C}$ for $6 \mathrm{hrs}$ (one-step growth experiment with m.o.i. of 0.08-50 PFU/cell) or $24 \mathrm{hrs}$ (multiple-step growth experiment with m.o.i. of $2 \times 10^{-6-} 2 \times 10^{0} \mathrm{PFU} /$ cell). DNA ladder analysis of mock- and virus-infected SRA01/04 cells indicated that (a) in the multiple-step growth experiment, EV70 infection at an m.o.i. $>2 \times 10^{-1}$ PFU/cell for $24 \mathrm{hrs}$ could induce apparent apoptotic DNA ladders (Fig. 1A), (b) in the one-step growth experiment $^{[22]}$, EV70 infection at an m.o.i. $>10$ PFU/cell could induce apoptotic DNA ladders (Fig. 1B) and (c) the apoptotic DNA ladders in the one-stepgrowth experiment with high m.o.i. is not as clear (smeared) as in the multiple-step growth experiment with a lower m.o.i. The results suggest that EV70 induced apoptosis is dose (or m.o.i.)-dependent.

It was reported that the ratio of necrosis/apoptosis during the $\beta$-cell death caused by coxsackievirus B5 increased with the increase of viral m.o.i. ${ }^{[23]}$. Therefore, the smeared apoptotic DNA ladders in the one-step viral growth experiment may be caused by both apoptosis and necrosis. APOPercentage dye uptake bioassay, according to Biocolor Ltd., is an apoptosis assay that can differentiate apoptosis from necrosis with a sensitivity of one single apoptotic cell ${ }^{[12]}$. Therefore, to confirm that EV70 induced dose-dependent apoptosis in human lens epithelial cells, confluent SRA01/04 cells in 96-well plates, infected by EV70 at the same concentrations and time as the apoptotic DNA 


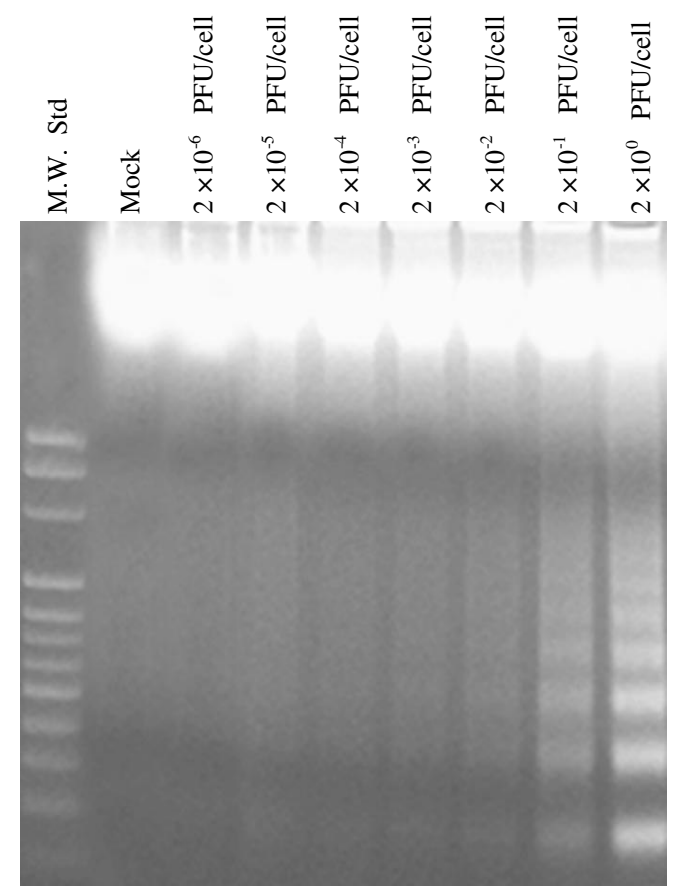

A

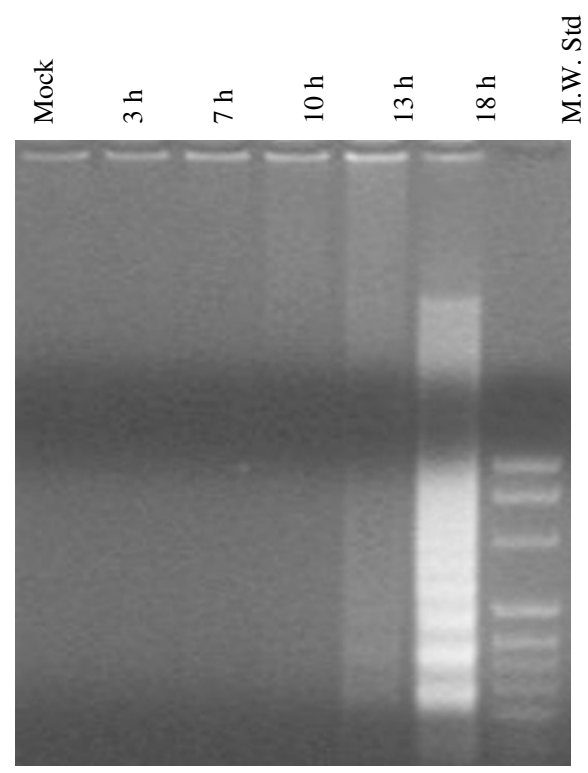

$\mathrm{C}$

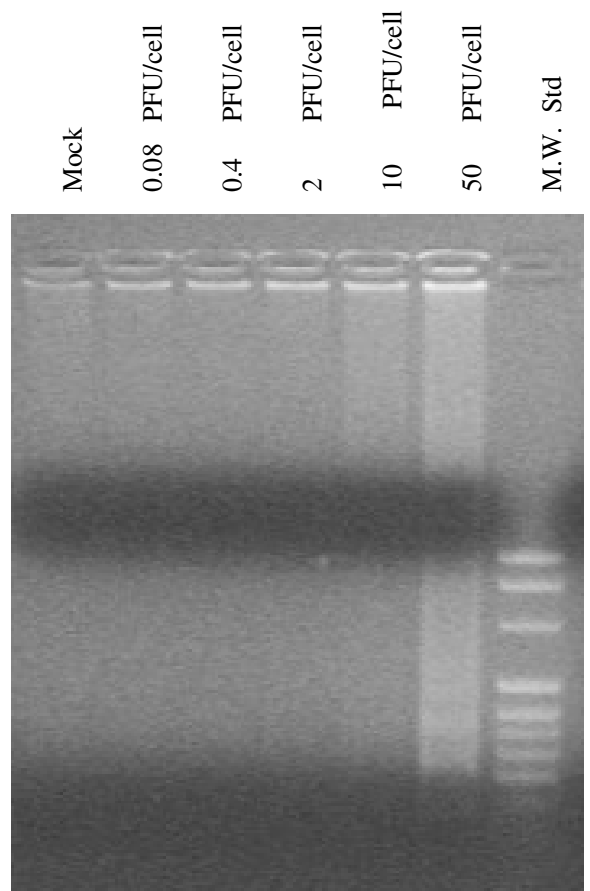

B

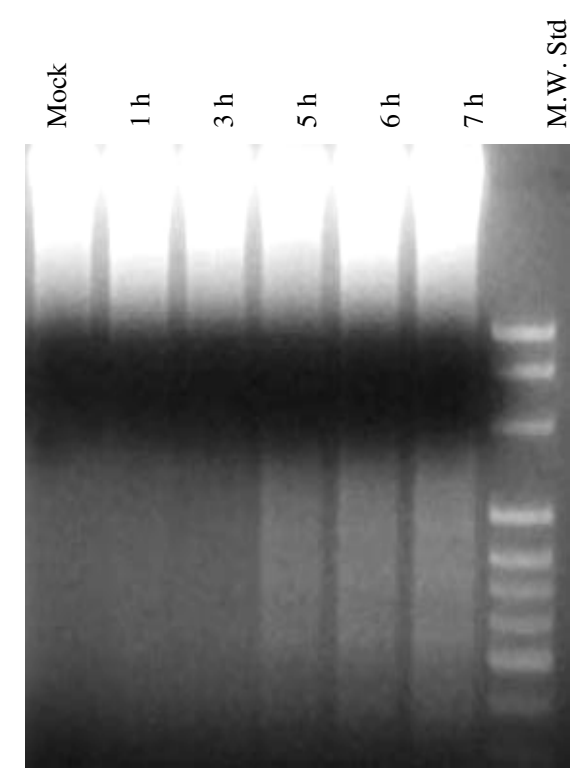

Fig. 1: EV70 J670/71 induces dose- and time-dependent apoptosis in human lens epithelial SRA01/04 cells. Confluent SRA01/04 cells (about 1 $\times 10^{6}$ cells/well) in 6-well plates were infected with different concentrations of EV70 (J670/71 strain) virus for $24 \mathrm{hrs}$ (A) or $6 \mathrm{hrs}$ (B), or infected with same concentration of EV70 (J670/71 strain) virus for 3-18 hrs (3-18 h) (C) or 1-7 hrs (1-7 h) (D). Mock- or virus-infected cells were harvested and processed for apoptotic DNA ladders. (A) Dose-dependent apoptosis of EV70 infected SRA01/04 cells at an m.o.i. of $2 \times 10^{-6}-2 \times 10^{0} \mathrm{PFU} /$ cell. Apparent apoptotic DNA ladders were detected in SRA01/04 cells infected with EV70 at an m.o.i. of $>2$ $\times 10^{-1} \mathrm{PFU} /$ cell for $24 \mathrm{~h}$. (B) Dose-dependent apoptosis of EV70 infected SRA01/04 cells at an m.o.i. of 0.08-50 PFU/cell. Apoptotic DNA ladders were detected in SRA01/04 cells infected with EV70 at an m.o.i. of $>10$ PFU/cell for $6 \mathrm{~h}$. (C) Time-dependent apoptosis of EV70 infected SRA01/04 cells at a low m.o.i. of 1.0 PFU/cell for 3-18 h. Apparent apoptotic DNA ladders were detected in SRA01/04 cells infected with EV70 at an m.o.i. of $1.0 \mathrm{PFU} / \mathrm{cell}$ for more than $13 \mathrm{~h}$. (D) Time-dependent apoptosis of EV70 infected SRA01/04 cells with EV70 at an m.o.i. of 25 PFU/cell for 1-7 h. Apparent apoptotic DNA ladders were detected in SRA01/04 cells with EV70 infected at an m.o.i. of $25 \mathrm{PFU} / \mathrm{cell}$ for more than $5 \mathrm{~h}$. (A) and (C) were performed while viral infection was in a multiple-step growth curve. (B) and (D) were performed while viral infection was in a one-step growth curve. M.W. Std. is the molecular standards 
Mock

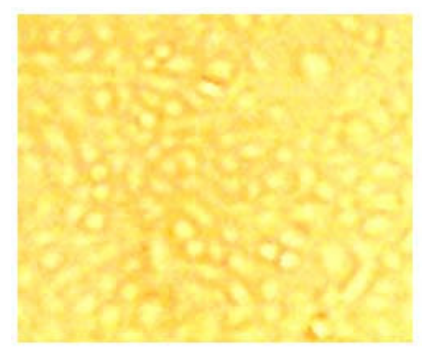

EV70 Infection (7h)

5 PFU/cell

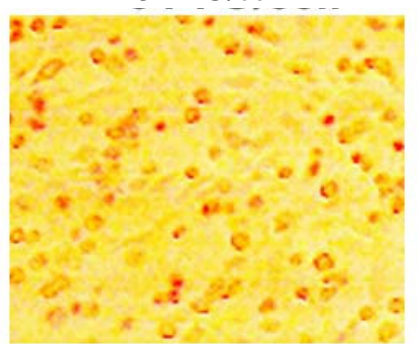

A
$50 \mathrm{PFU} / \mathrm{cell}$

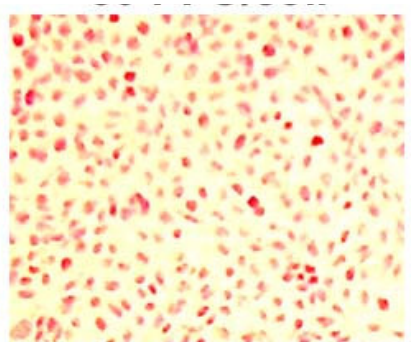

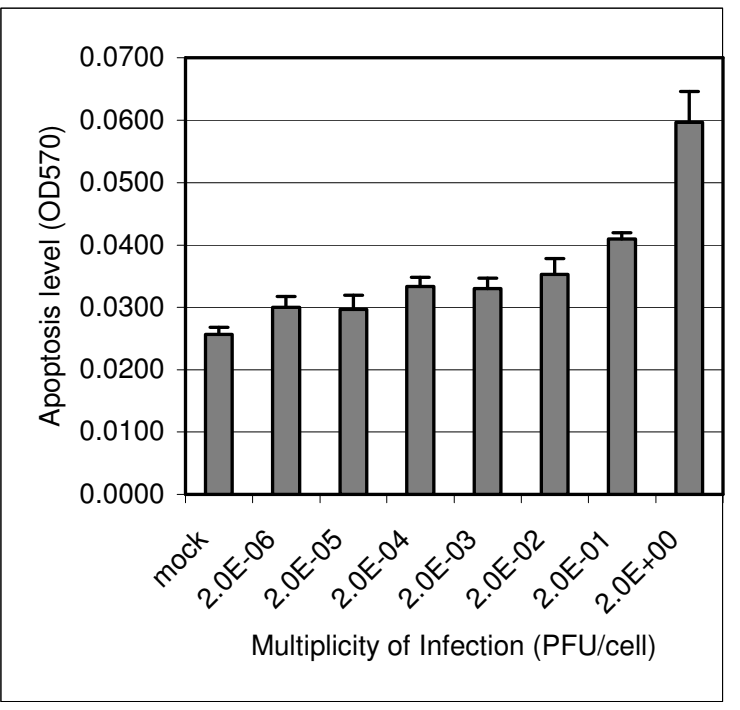

B

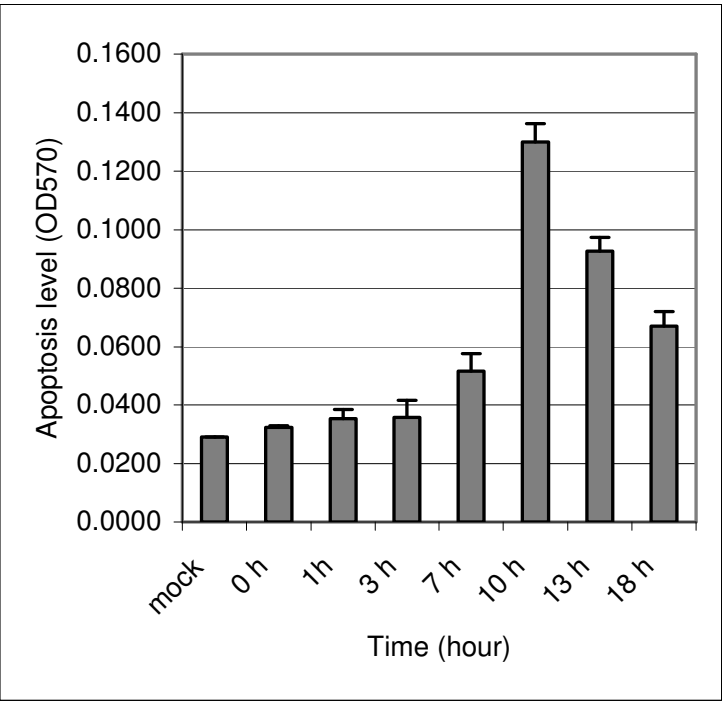

D

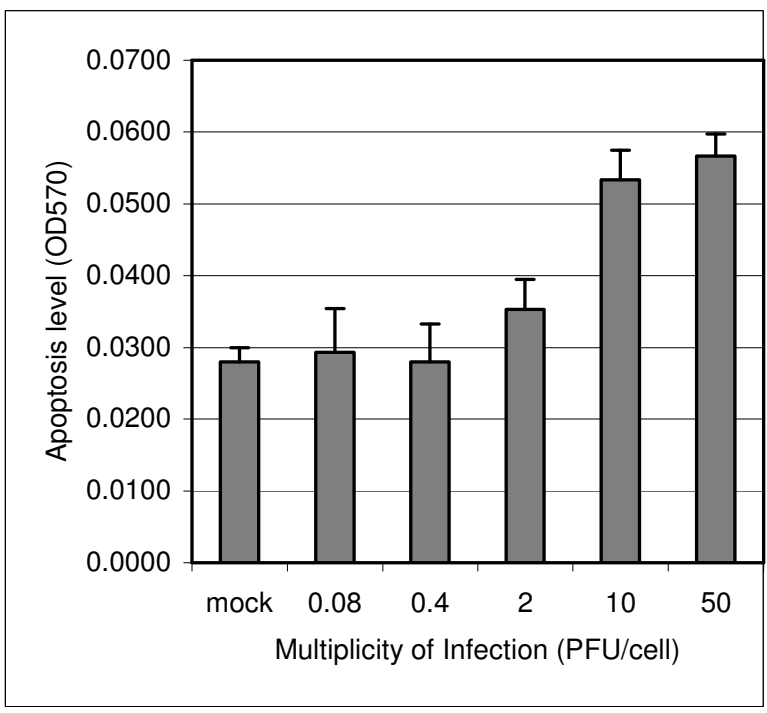

C

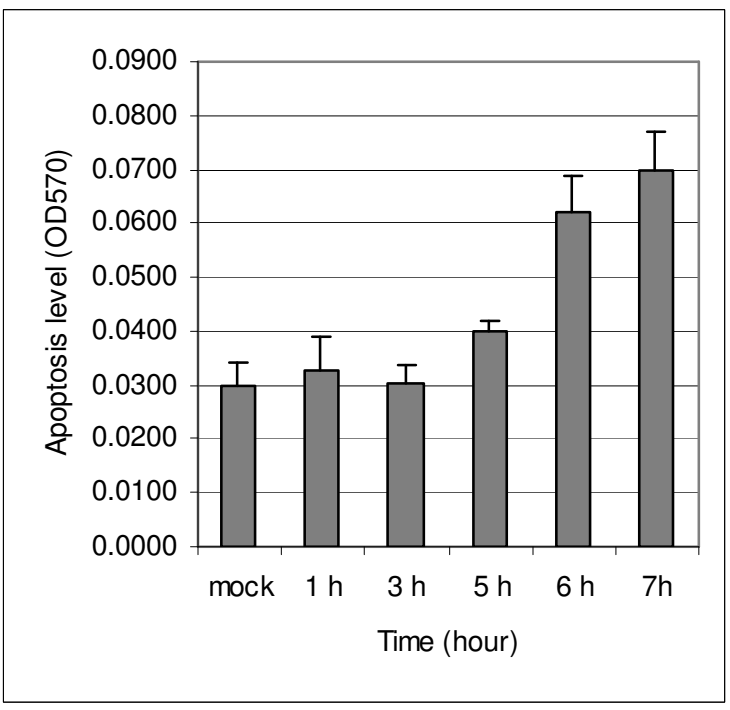

$\mathrm{E}$

Fig. 2: Detection of EV70 J670/71 induced dose- and time-dependent apoptosis of SRA01/04 cells by APOPercentage dye uptake bioassay. Confluent SRA01/04 cells (about $4 \times 10^{4}$ cells/well) in 96-well plates were infected with different concentrations of EV70 (J670/71 strain) virus for $7 \mathrm{hrs} \mathrm{(A),} 24 \mathrm{hrs}$ (B) or $6 \mathrm{hrs}(\mathrm{C})$, or infected with same concentration of EV70 (J670/71 strain) virus for 0-18 hrs (0-18 h) (D) or 1-7 hrs (1-7 h) (E). Apoptosis of mock- or virus-infected cells was detected by APOPercentage dye uptake bioassay. The multiplicity and time of EV70 J670/71 infection in (B), (C), (D) and (E) were the same as those in Fig 1A, 1B, 1C and 1D respectively. (A) Photos of mock- and EV70 (5 and 50 PFU/cell) infected (7 h p.i.) SRA01/04 cells stained by APOPercentage dye. (B) Dosedependent apoptosis of EV70 infected SRA01/04 cells at an m.o.i. of $2 \times 10^{-6}-2 \times 10^{0} \mathrm{PFU} / \mathrm{cell}$ for $24 \mathrm{~h}$. (C) Dose-dependent apoptosis of EV70 infected SRA01/04 cells at an m.o.i. of 0.08-50 PFU/cell for $6 \mathrm{~h}$. (D) Time-dependent apoptosis of EV70 infected SRA01/04 cells at a low m.o.i. of 1.0 PFU/cell for 0-18 h. (E) Time-dependent apoptosis of EV70 infected SRA01/04 cells with EV70 at an m.o.i. of 25 PFU/cell for 1-7 h. (A), (C) and (E) were performed while viral infection was in a one-step growth curve. (B) and (D) were performed while viral infection was in a multiple-step growth curve. Data in (B), (C), (D) and (E) are means \pm S.E. of 3 parallel experiments 
Am. J. Infectious Dis. 1 (2):90-106, 2006

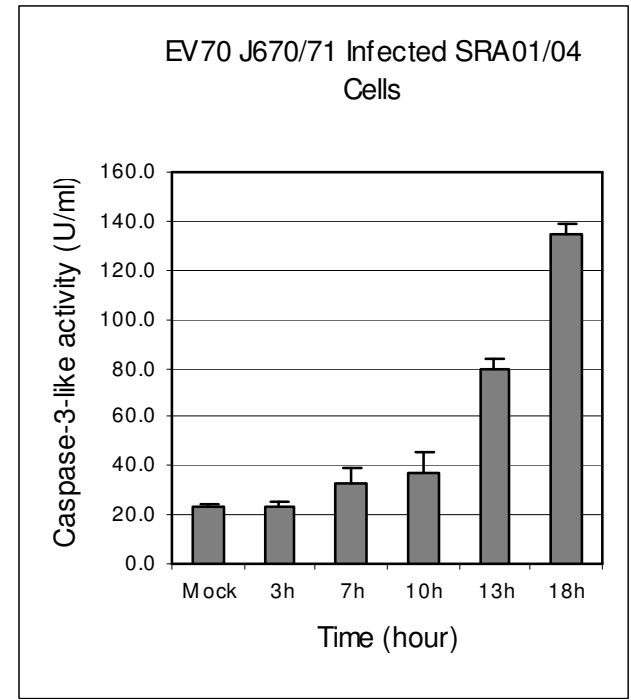

A

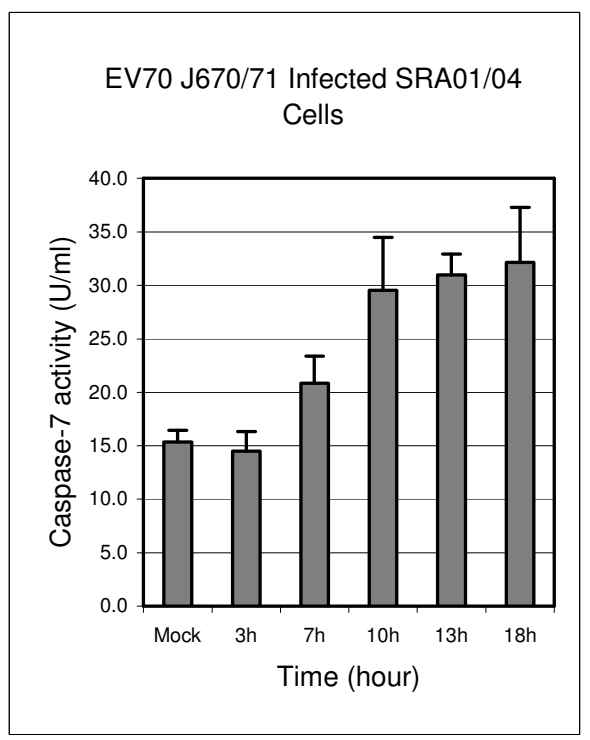

C

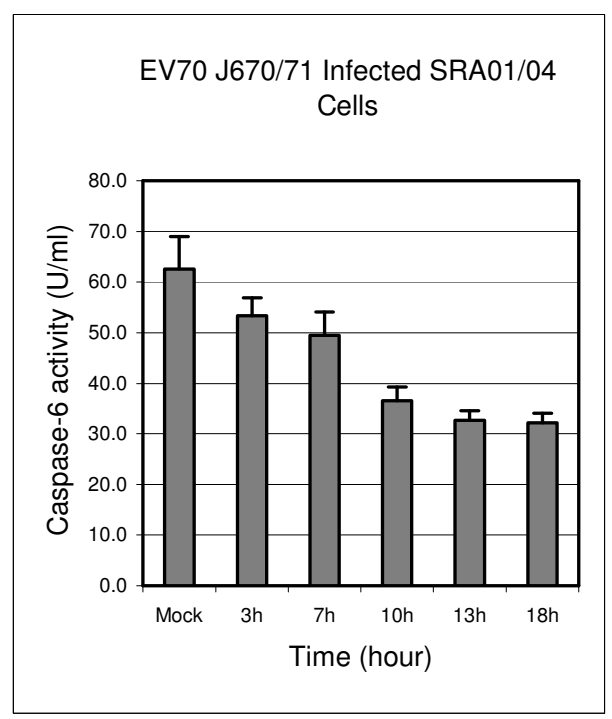

E

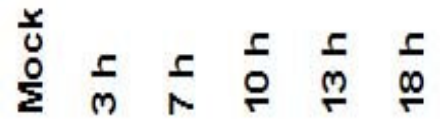

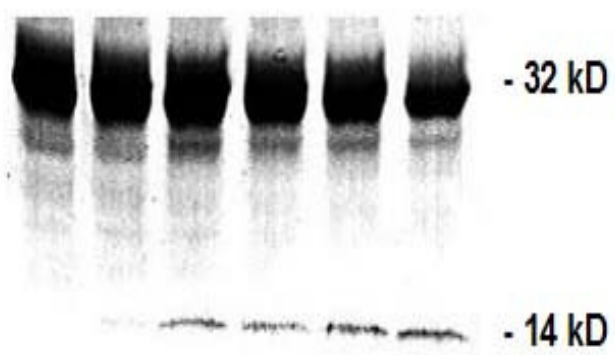

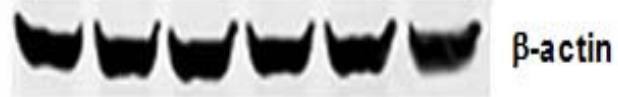

B

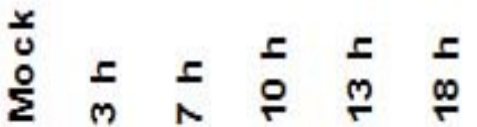

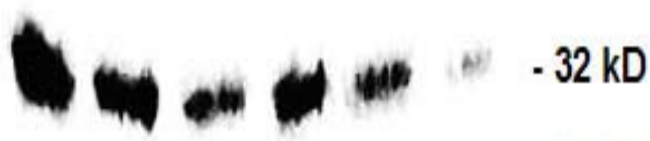

4i. $-26 \mathrm{kD}$

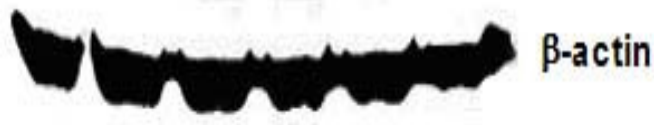

D

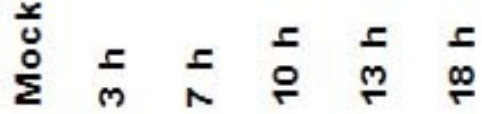

$\begin{array}{lll} & -32 \mathrm{kD} \\ b & -26 \mathrm{kD}\end{array}$

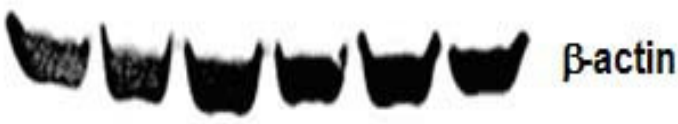
F 


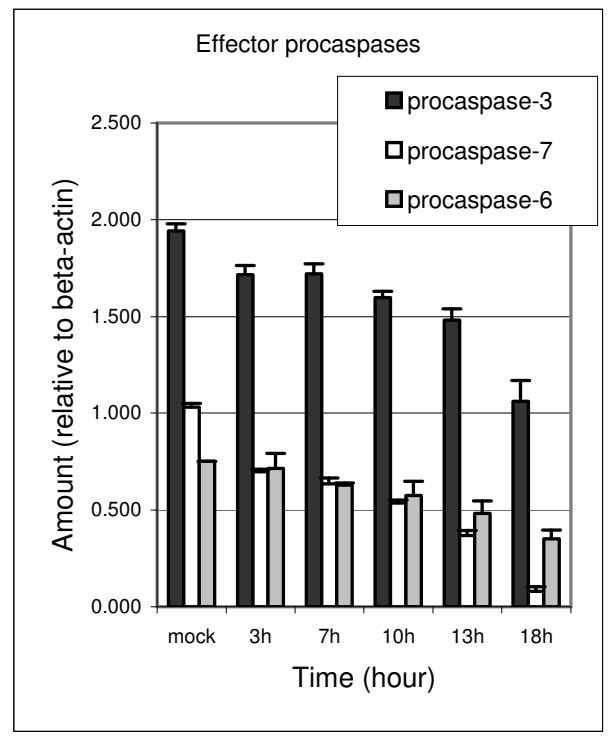

G

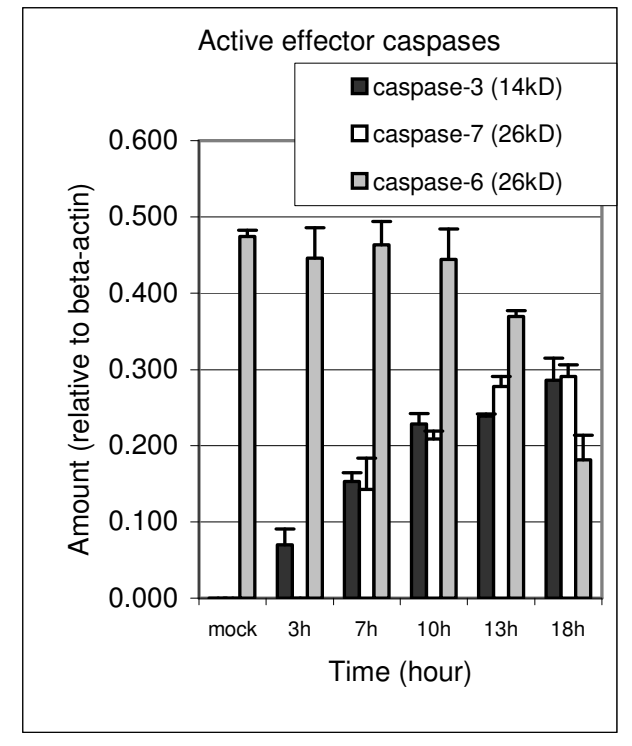

$\mathrm{H}$

Fig. 3: Activation of effector caspases of SRA01/04 cells during multiple-step viral growth of EV70 J6 70/71. Confluent human lens epithelial SRA01/04 cells in 6-well plates were infected with EV70 (J670/71 strain) virus (m.o.i. = 1.0 PFU/cell) for different time (3-18 h). Mockand virus-infected cells were harvested and processed for enzymatic activity study (A, C, E) of caspase-3, 6 and 7 or for Western blotting analysis of the proteins of caspase-3, 6 and 7 (B, D, F, G and H). In (B), (D), (F), (G) and (H), each lane contained $40 \mu \mathrm{g}$ of total proteins of the whole-cell lysates of mock- or EV70-infected cells, and $\beta$-actin (42 kD) was the internal control. (A) Caspase-3-like activity induced by EV70 infection. EV70 infection for $7 \mathrm{~h}, 10 \mathrm{~h}, 13 \mathrm{~h}$ and $18 \mathrm{~h}$ but not $3 \mathrm{~h}$ significantly increased caspase-3-like activity (p < 0.01) (B) Activation of caspase-3. The 32-kD doublets were the inactive caspase-3 or procaspase-3 of SRA01/04 cells. The 14-kD band was viral infection-activated (cleaved) forms of caspase-3 protein of SRA01/04 cells. (C) Caspase-7 activity induced by EV70 infection. EV70 infection for $7 \mathrm{~h}, 10 \mathrm{~h}, 13 \mathrm{~h}$ and $18 \mathrm{~h}$ but not $3 \mathrm{~h}$ significantly increased caspase-7 activity $(\mathrm{p}<0.01)$ but $10 \mathrm{~h}, 13 \mathrm{~h}$ and $18 \mathrm{~h}$ of EV70 infection had no significant differences ( $p>0.05$ ) (D) Activation of caspase-7. The 32-kD band was the inactive caspase-7 or procaspase-7 of SRA01/04 cells. The 26-kD band was a viral infection-activated (cleaved) form of caspase-7 protein of SRA01/04 cells. (E) Caspase-6 activity induced by EV70 infection. EV70 infection for $7 \mathrm{~h}, 10 \mathrm{~h}, 13 \mathrm{~h}$ and $18 \mathrm{~h}$ but not $3 \mathrm{~h}$ significantly decreased caspase-6 activity $(\mathrm{p}<0.01)$ but $13 \mathrm{~h}$ and $18 \mathrm{~h}$ of EV70 infection had no differences ( $\mathrm{p}=0.6261)$ (F) Activation of caspase-6. The 32-kD doublets were the inactive caspase- 6 or procaspase- 6 of SRA01/04 cells. The $26-\mathrm{kD}$ band in control and virus-infected cells was an active (cleaved) form of caspase-6 protein of SRA01/04 cells. (G) The protein amounts (relative to $\beta$-actin) of 3 human effector procaspases (all $32 \mathrm{kD}$ ) on Western blots, decreased with the time of EV70 infection (1.0 PFU/cell), especially after $10 \mathrm{~h}$ post infection (p.i.). Procaspase3 protein level was higher than those of procaspases- 7 and 6 proteins at any time points. (H) The protein amounts (relative to $\beta$-actin) of 3 human active effector procaspases changed with the time of EV70 infection (1.0 PFU/cell) on Western blots. The protein levels of active caspase-3 $(14 \mathrm{kD})$ and caspase-7 $(26 \mathrm{kD})$ steadily increased while that of constitutively activated caspase-6 (26 kD) decreased with EV70 infection time. Data shown in $(\mathrm{A}),(\mathrm{C}),(\mathrm{E}),(\mathrm{G})$ and $(\mathrm{H})$ are means \pm S.E. of 3 parallel experiments

laddering, were analyzed by APOPercentage dye uptake bioassay (Fig. 2A, 2B and 2C). Comparison of Fig. 1A with Fig. 2B, revealed that apoptotic DNA laddering is much less sensitive than APOPercentage assay for the analysis of EV70 induced apoptosis. The results of APOPercentage assay indicated that in both the one-step viral growth experiment (0.08-50 PFU/cell, $7 \mathrm{~h}$ or $6 \mathrm{~h}$ ) (Fig. 2A or 2C) and the multiple-step viral growth experiment $\left(2 \times 10^{-6-} 2 \times 10^{0} \mathrm{PFU} / \mathrm{cell}, 24 \mathrm{~h}\right)$ (Fig. 2B), EV70 induced apoptosis of SRA01/04 cells was dose- or m.o.i.-dependent.

To test whether EV70 induced apoptosis is timedependent, SRA01/04 cells in 6-well plates were first infected with EV70 J670/71 at $37^{\circ} \mathrm{C}$ at an m.o.i. of 10 $\mathrm{PFU} /$ cell for 1-7 hrs (one-step growth experiment) or at an m.o.i. of 1.0 PFU/cell for 3-18 hrs (multiple-step growth experiment). Apoptotic DNA ladder analysis indicated that (a) in the multiple-step growth experiment, $13 \mathrm{hrs}$ of EV70 infection at an m.o.i. of 1.0 $\mathrm{PFU} /$ cell began to induce apoptotic DNA ladders
(Fig. 1C), (b) in the one-step growth experiment, around $5 \mathrm{hrs}$ of EV70 infection at an m.o.i. of 10 PFU/cell began to induce detectable apoptotic DNA ladders in SRA01/04 cells (Fig. 1D) and (c) the apoptotic DNA ladders in the one-step-growth experiment with high m.o.i. is also smeared and not as clear as in the multiple-step growth experiment with a lower m.o.i.. The results suggest that in SRA01/04 cells, (a) EV70 induced apoptosis in a time-dependent manner and (b) high EV70 m.o.i. in a one-step growth experiment induced faint apoptotic DNA ladders.

APOPercentage dye uptake bioassay of SRA01/04 cells in 96-well plates, which were treated the same as above, indicated that (a) in the multiple viral growth experiment (1.0 PFU/cell $0 \mathrm{~h}-18 \mathrm{~h})$, EV70 induced apoptosis level increased with viral infection time prior to $10 \mathrm{~h}$ p.i. (Fig. 2D) and thereafter decreased (this was some different from the results of apoptotic DNA laddering in Fig. 1C), which was because APOPercentage dye uptake bioassay only detects 
apoptotic cells during the early stages of apoptosis (prior to their lysis) and the SRA01/04 cells lysed by apoptosis after $10 \mathrm{~h}$ p.i. cannot been detected with this assay (data not shown); and (b) in the one-step viral growth experiment (25 PFU/cell, 1 h-7 h), EV70 induced apoptosis level increased with viral infection time (Fig. 2E), which correlated with the apoptotic DNA ladders (Fig. 1D). Therefore, the results confirmed that EV70 induced apoptosis of SRA01/04 cells are time-dependent.

EV70 induced apoptosis of SRA01/04 cells depends on the activation of effector caspase- 3 and caspase-7 but not caspase-6: To determine whether EV70 infection activates the 3 effector-caspases of human lens epithelial cells, SRA01/04 cells in 6-well plates were infected with EV70 J670/71 at an m.o.i. of 1.0 PFU/cell at $37^{\circ} \mathrm{C}$ for 3-18 hrs (Fig. 3). The measured caspase-3-like activity (Fig. 3A), composed of the activities of both caspases-3 and 7, increased over the time of EV70 infection in SRA01/04 cells with the former as the main component (compared Fig. 3A with Fig. 3C). Western blotting with antibody to human caspase-3 (Fig. 3B) indicated that (a) the procaspase-3 of SRA01/04 cells was $32 \mathrm{kD}$ since only this band/doublets was detected in the mock control, (b) during EV70 J670/71 infection, the procaspase-3 (32 $\mathrm{kD})$ was cleaved and produced a $14 \mathrm{kD}$ band-a detectable form of caspase-3 and (c) the levels of the 32 $\mathrm{kD}$ procaspase-3 form (Fig. 3G) decreased while the 14-kD band (Fig. 3H) increased over the time course of EV70 J670/71 infection, correlating with the increasing of caspase-3 enzyme activity. The results suggest that (a) EV70 infection induced caspase-3 activation in SRA01/04 cells by cleaving procaspase-3 into low molecular weight active forms of caspase-3 (such as the 14-kD protein) and (b) the expression of procaspase-3 protein was not up-regulated during EV70 induced apoptosis.

Similarly, enzymatic assay indicated that the measured caspase-7 activity also increased over the time course of EV70 J670/71 infection of SRA01/04 cells in the above multiple-step viral growth experiment (Fig. 3C). Western blotting with antibody to human caspase-7 (Fig. 3D) indicated that (a) the procaspase-7 of SRA01/04 cells was a $32 \mathrm{kD}$ band found in the mock control, (b) this procaspase-7 (32 kD) was cleaved into a detectable form of caspase-7 $(26 \mathrm{kD})$ in EV70 infected SRA01/04 cells and (c) the levels of the procaspase-7 (32 kD) (Fig. 3G) decreased while the 26$\mathrm{kD}$ form of caspase-7 (Fig. 3H) increased over the time course of EV70 J670/71 infection, correlating with increasing caspase-7 enzyme activity. The results suggest that (a) EV70 infection induced caspase-7 activation in SRA01/04 cells by cleaving 32-kD procaspase-3 into low molecular weight active forms of caspase-7, such as the $26-\mathrm{kD}$ form and (b) the expression of procaspase-7 protein was not upregulated during EV70 induced apoptosis.

In contrast to the above caspase- 3 and 7 results, there was a high background caspase- 6 activity in mock control SRA01/04 cells, which decreased over the time course of EV70 J670/71 infection in the above multiple-step viral growth experiment (Fig. 3E). Western blotting with antibody to human caspase-6 (Fig. 3F) indicated that (a) there were 2 forms of caspase- 6 protein in the mock control as well as in the EV70-infected SRA01/04 cells (26 kD and $32 \mathrm{kD})$ and (b) the levels of the $32 \mathrm{kD}$ form and the $26 \mathrm{kD}$ form of caspase- 6 protein both decreased over the time of EV70 J670/71 infection (Fig. 3G and 3H), correlating with decreasing caspase- 6 enzymatic activity. Therefore, the results suggest that (a) the $32 \mathrm{kD}$ or the $26 \mathrm{kD}$ caspase6 protein was not over-expressed during EV70 induced apoptosis and (b) during a multiple-step viral growth experiment, lengthy EV70 infection resulted in the degradation of both $32 \mathrm{kD}$ and $26 \mathrm{kD}$ forms of caspase6 proteins.

Taken together, the above results suggest that (a) EV70 induced apoptosis of SRA01/04 cells is dependent on the activation of caspase- 3 and caspase- 7 but not caspase- 6 and (b) the gradual time-dependent caspase-3 and/or caspase-7 activation(s) (Fig. 3A-3D) correlated well with the time-dependent change in the intensity of the apoptotic DNA ladders (Fig. 1C).

Caspase inhibitor IX inhibits EV70 induced apoptosis, caspase-3 activation of SRA01/04 cells and subsequent EV70 progeny virus release: Caspase inhibitor IX (Z-VD-FMK) (a broad-range cellpermeable and irreversible caspase inhibitor capable of inhibiting caspase-1, 3, 6, 7, 8 and 9, etc) was found to dose-dependently inhibit EV70 induced apoptosis of SRA01/04 cells (data not shown) between 0.2-25 $\mu \mathrm{M}$. To determine the effect of Z-VD-FMK at different addition time on the inhibition of EV70 induced apoptosis, a final concentration of $10 \mu \mathrm{M}$ was added at 0-7 h p.i. to confluent human lens epithelial SRA01/04 cells in 6-well plates infected with EV70 J670/71 at an m.o.i. of 1.0 PFU/cell. In this multiple-step viral growth experiment (Fig. 4), Z-VD-FMK (Z-VD in the figure) greatly inhibited EV70 induced apoptotic DNA ladders of SRA01/04 cells when the inhibitor was added prior to $4 \mathrm{~h}$ p.i. with no significant differences between $0 \mathrm{~h}-4$ h p.i. (Fig. 4A). At the same time, addition of Z-VDFMK also greatly inhibited EV70 induced caspase-3like activity (measured at $8 \mathrm{~h}$ p.i.) of SRA01/04 cells by $88 \%, 85 \%, 88 \%$ and $31 \%$ respectively, at $0 \mathrm{~h}, 1 \mathrm{~h}, 4 \mathrm{~h}$ and 7 h p.i ( $p<0.01$ while compared with EV70 control) (Fig. 4B), with no significant differences prior to 4 h p.i. $(\mathrm{p}>0.1)$.

Extracellular and intracellular EV70 titers for the above experiments were also measured (Fig. 4C). Addition of Z-VD-FMK at $0 \mathrm{~h}, 1 \mathrm{~h}, 4 \mathrm{~h}$ or $7 \mathrm{~h}$ post 


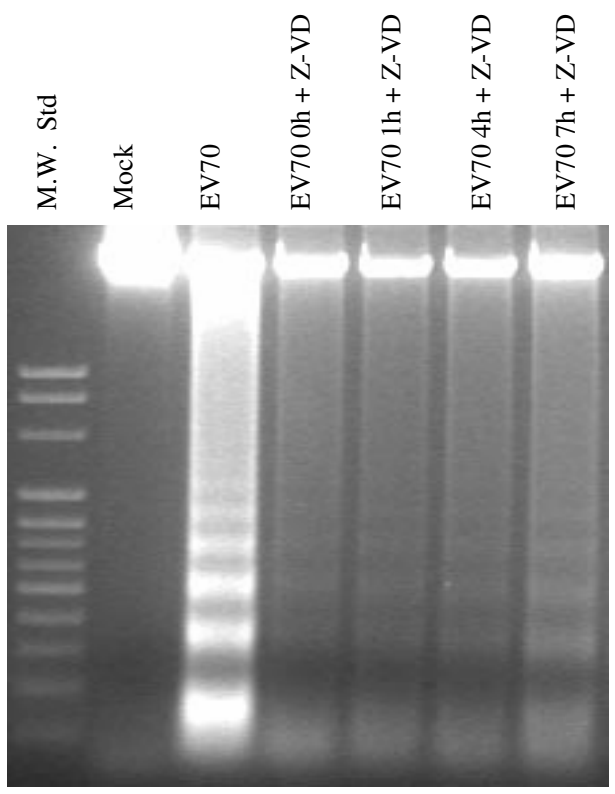

A

Effects of Caspase Inhibitor IX (ZVD ) on EV70 Production

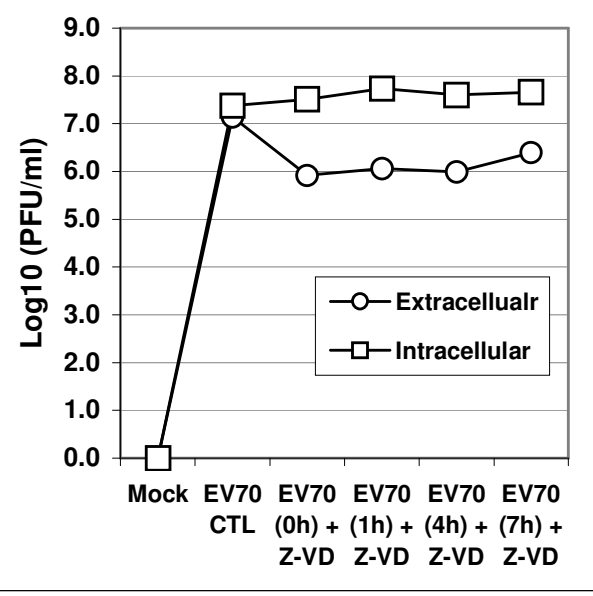

C

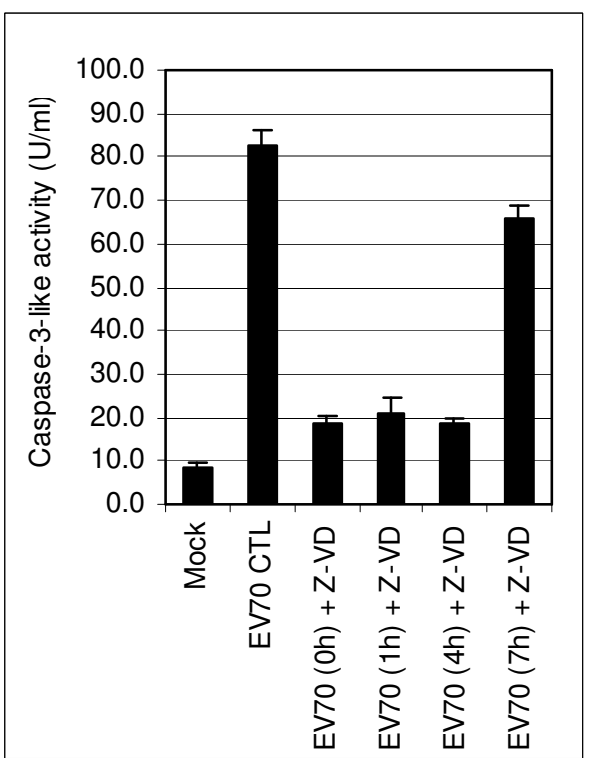

B

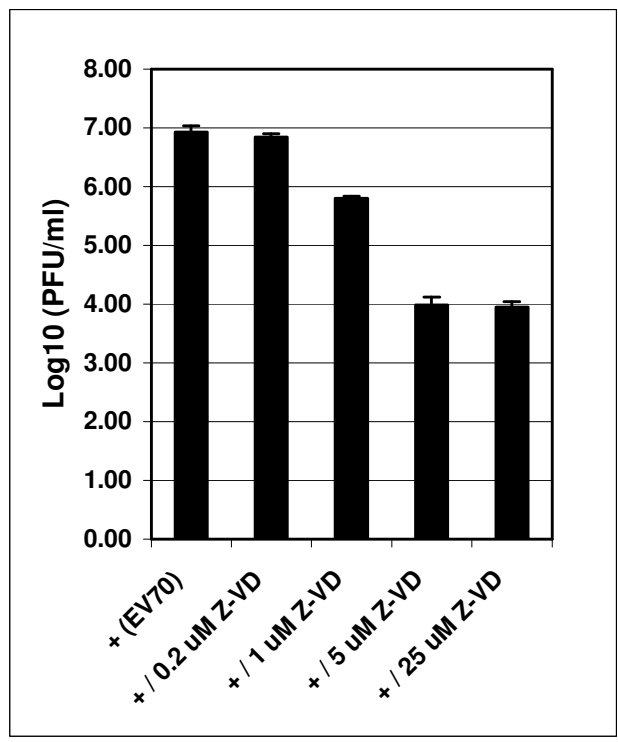

D

Fig. 4: Z-VD-FMK inhibited the apoptotic DNA ladders and caspase-3 like activity of EV70 J670/71 infected SRA01/04 cells and extracellular virus production. SRA01/04 cells (about $1 \times 10^{6}$ cells) in 6-well plates were infected with EV70 (J670/71 strain) virus at an m.o.i. of 1 PFU/cell. Z-VD-FMK (caspase inhibitor IX) was added to the virus-cell cultures (A, B and C) at the final concentration of $10 \mu \mathrm{M}$ at different time $(0-7 \mathrm{~h})$ post infection (p.i.), or at different final concentration $(0.2-25 \mu \mathrm{M})$ at $0 \mathrm{~h}$ p.i.. After total $18 \mathrm{hrs}(\mathrm{A}, \mathrm{C}$ and $\mathrm{D})$ or $8 \mathrm{hrs}$ (B) of incubation p.i., the cells were harvested and media were collected. (A) Apoptotic DNA ladders. Addition of Z-VD-FMK (Z-VD) at 0-4h p.i. significantly inhibited EV70 induced apoptotic DNA ladders of SRA01/04 cells while addition of Z-VD-FMK (Z-VD) at $7 \mathrm{~h} \mathrm{p.i.}$ greatly reduced the strength of EV70 induced apoptotic DNA ladders. M.W. Std. is the molecular standards. (B) Caspase-3 activity analysis. Addition of Z-VD-FMK (Z-VD) at $0-4 \mathrm{~h}$ p.i. very significantly inhibited virus-induced caspase-3 activity $(85-88 \%$ inhibition, $\mathrm{p}$ $<0.01$ ). Addition of Z-VD at $7 \mathrm{~h}$ p.i. also very significantly inhibited virus-induced caspase-3 activity but inhibition rate was much lower (31\% inhibition, $\mathrm{p}<<0.01)$. (C) EV70 titers (PFU/ml) in the media of cells after EV70 infection (Extracellular viral titer-time curve) or in the virus-infected cells lysis extracts (Intracellular viral titer-time curve). Addition of Z-VD-FMK (Z-VD) at 0-4 h p.i., very significantly inhibited the extracellular EV70 titers (91.8-94.1\% inhibition, $\mathrm{p} \ll 0.01$ ). Addition of Z-VD at $7 \mathrm{~h}$ p.i. also very significantly inhibited the extracellular EV70 titers with much lower inhibition rate $(82.2 \%$ inhibition, $\mathrm{p}<<0.01)$. In contrast, the addition of Z-VD at 0-7 h p.i. increased intracellular EV70 titers by about 35.5-129.4\%. (D) Dose-dependent inhibition of extracellular EV70 virus production by Z-VD-FMK $(0.2-25 \mu \mathrm{M})$. Data shown in (B) and (D) are means \pm S.E. of 3 parallel experiments 
Am. J. Infectious Dis. 1 (2):90-106, 2006

A

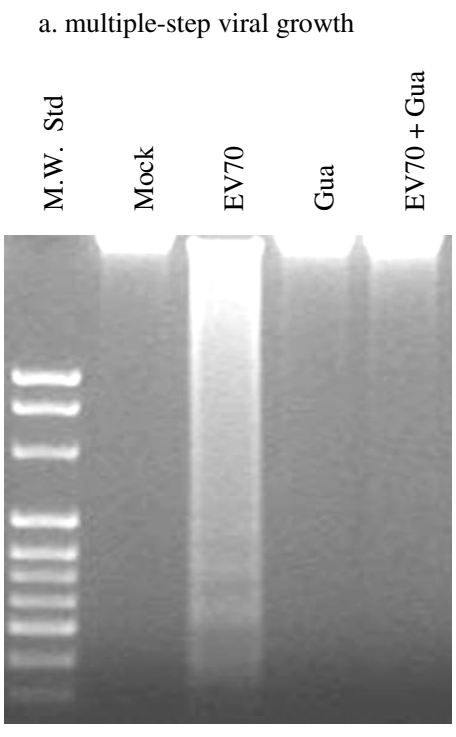

a. multiple-step viral growth

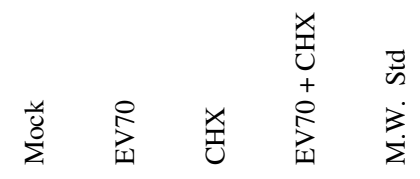

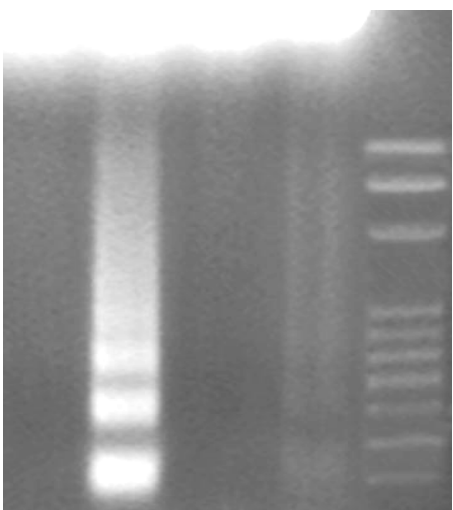

b. one-step viral growth

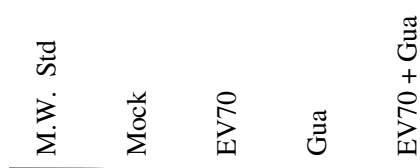

b. one-step viral growth

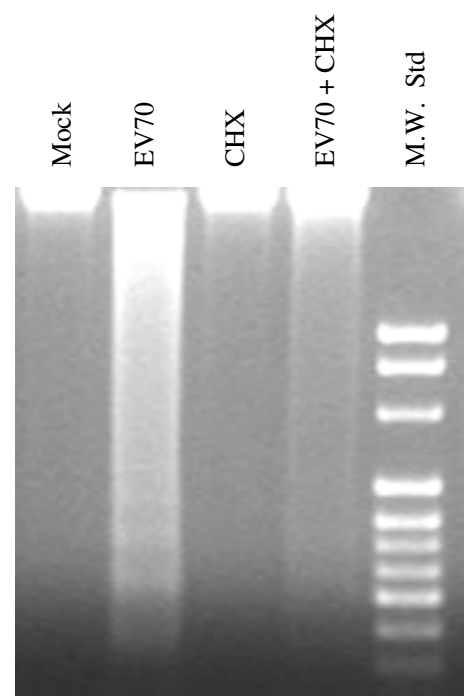




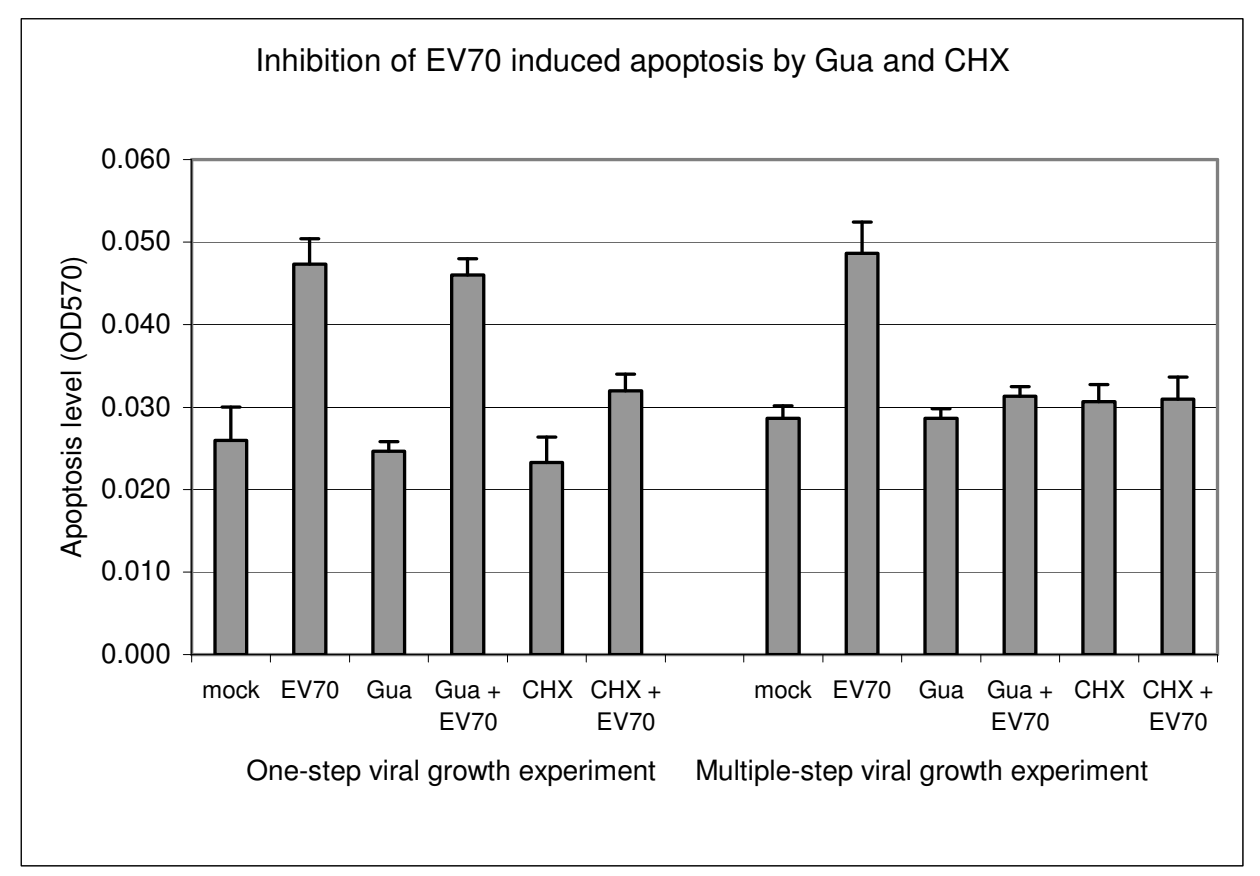

D

Fig. 5: Effects of UV- or heat-inactivation, guanidine $\cdot \mathrm{HCl}$ and cycloheximide on EV70 J670/71 induced apoptosis of SRA01/04 cells. Mock- and virus-infected SRA01/04 cells (w/o chemicals) as well as SRA01/04 cells for chemical controls in 6-well plates were harvested and analyzed for apoptotic DNA ladders (A, B and C), and similarly treated SRA01/04 cells in 96-well plates were analyzed by APOPercentage dye uptake bioassay (D). M.W. Std. is the molecular standards. (A) UV- or heat inactivated EV70 did not induce apoptosis of SRA01/04 cells. Confluent SRA01/04 cells in 6-well plates were infected with wild type (infectious), UV-inactivated or heatinactivated EV70 (wt EV70, UV-EV70 and $\Delta$ EV70 respectively) at an m.o.i. of 1.0 PFU/cell for $20 \mathrm{~h}$. UV-EV70 and $\Delta$ EV70 were obtained by inactivation of wt EV70 with $250 \mathrm{~mJ}$ of UV or heating at $56^{\circ} \mathrm{C}$ or $65^{\circ} \mathrm{C}$ for half an hour. (B) Guanidine $\mathrm{HCl}$ (Gua) inhibited EV70 induced apoptosis of SRA01/04 cells while viral growth was of multiple-step (m.o.i. $=1.0 \mathrm{PFU} / \mathrm{cell}, 18 \mathrm{~h}$ ), but did not while viral growth was of one-step (m.o.i. $=20$ PFU/cell, 7 h). (C) Cycloheximide (CHX) inhibited EV70 induced apoptosis of SRA01/04 cells while viral growth was of multiple-step (m.o.i. $=1.0 \mathrm{PFU} / \mathrm{cell}, 18 \mathrm{~h}$ ) and of one-step (m.o.i. $=20 \mathrm{PFU} / \mathrm{cell}, 7 \mathrm{~h}$ ). (D) Quantitation of EV70 induced apoptosis inhibited by Gua $(100 \mu \mathrm{g} / \mathrm{ml})$ and CHX $(2.5 \mu \mathrm{g} / \mathrm{ml})$. In one-step viral growth experiment (20 PFU/cell, $7 \mathrm{~h})$, Gua did not $(\mathrm{p}=0.5614)$ while CHX significantly inhibited EV70 induced apoptosis by 59.4\% ( $\mathrm{p}=0.0019)$. In multiple-step viral growth experiment (1.0 PFU/cell, $18 \mathrm{~h}$ ), both Gua and CHX significantly inhibited EV70 induced apoptosis by $86.7 \%(\mathrm{p}=0.0016)$ and $98.3 \%(\mathrm{p}$ $=0.0027)$ respectively. Data shown in (D) are means \pm S.E. of 3 parallel experiments

EV70 infection increased intracellular EV70 infectious virus levels to $1.35,2.29,1.68$ and 1.92 folds, respectively (Fig. 4C, intracellular virus titer-treatment curve), while at the same time significantly decreased the extracellular virus levels released from SRA01/04 cells by $94.1 \%, 91.8 \%, 93 \%$ and $82.2 \%$, respectively (Fig. 4C, extracellular virus titer-treatment curve). In addition, there were no significant differences in the inhibition of extracellular EV70 titers between the additions of Z-VD-FMK at $0 \mathrm{~h}, 1 \mathrm{~h}$ and $4 \mathrm{~h}$ p.i. ( $\mathrm{p}>$ 0.1) (Fig. 3C, extracellular virus titer-treatment curve). The results indicate that inhibition of EV70 induced apoptosis or caspase-3-like activity reduced EV70 progeny virus release into extracellular culture medium while allowing the accumulation of intracellular EV70. Z-VD-FMK at final concentrations of $0.2-25 \mu \mathrm{M}$ at $0 \mathrm{~h}$ post EV70 infection, dose-dependently inhibited extracellular EV70 titers (Fig. 4D), confirming the above result. Therefore, the results suggest that EV70 induced apoptosis and/or caspase- 3 and caspase-7 can serve as part of a mechanism for releasing progeny virus from SRA01/04 cells.
EV70 induced apoptosis of SRA01/04 cells requires infectious virus and depends on the syntheses of viral proteins but not viral genome RNA: To determine whether inactivated EV70 virions are capable of inducing apoptosis in human lens epithelial cells, confluent SRA01/04 cells in 6-well plates were infected at $37^{\circ} \mathrm{C}$ with $1.0 \mathrm{PFU} / \mathrm{cell}$ of native infectious (wt EV70), UV-inactivated (UV-EV70) or heat-inactivated ( $\triangle$ EV70) EV70 J670/71 for 20 hrs (Fig. 5A). Apoptotic DNA ladder analysis of the mock-infected and virusinfected SRA01/04 cells showed that: wtEV70 virions induced apoptosis while mock- infection or infection with inactivated UV-EV70 (250 mJ UV) or $\triangle E V 70$ $\left(56^{\circ} \mathrm{C} 30\right.$ min-heat or $65^{\circ} \mathrm{C} 30$ min-heat) did not. UVEV70 contains damaged viral RNA genome and normal functional viral proteins while $\triangle \mathrm{EV} 70$ harbors heatdenatured viral key proteins and a native intact viral genome. Therefore, the results suggest that UVinactivation or heat-inactivation of EV70 results in the loss of its capability to induce apoptosis (i.e., only wild type or native infectious EV70 is capable of inducing apoptosis in SRA01/04 cells). 


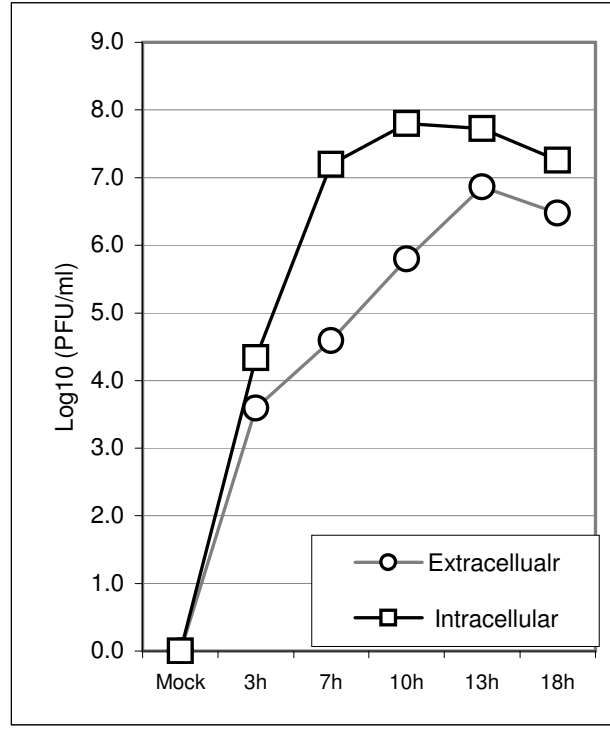

A
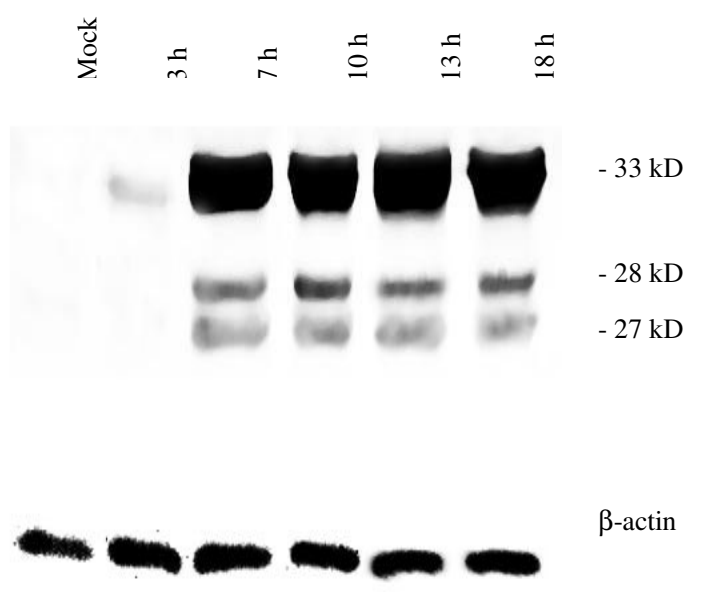

B

Fig. 6: Kinetics of viral major capsid protein syntheses during multiple-step growth of EV70 J6 70/71. Confluent human lens epithelial SRA01/04 cells in 6-well plates were infected with EV70 (J670/71 strain) virus (m.o.i. = 1.0 PFU/cell) for different time (3-18 h). (A) Intracellular and extracellular EV70 titer changes. Culturing media or the cells lysis extracts of mock or virus-infected HCC cells (supernatants of cell lysates-cells lysed in $200 \mu \mathrm{l}$ of PBS by 3 cycles of freeze-and-thaw-centrifuged at 15,000 $\times \mathrm{g}$ for $5 \mathrm{~min}$ ) were obtained for determining extracellular (medium) or intracellular (the cell lysis extract) EV70 titers (PFU/ml). Data shown in (A) are means of 3 parallel experiments. (B) Expression kinetics of EV70 major capsid proteins. Mock and virus-infected cells were harvested and processed for Western blotting analysis of EV70 major capsid proteins VP1, VP2 and VP3 (B). Each lane contained $40 \mu \mathrm{g}$ of total proteins of the whole-cell lysates of mock or EV70-infected cells, and $\beta$-actin (42 kD) was the internal control

Native infectious wtEV70 is capable of replication that requires the syntheses of EV70 viral genome RNA and viral proteins. To determine whether EV70 viral RNA synthesis is involved in the process of EV70 induced apoptosis, SRA01/04 cells were infected with EV70 J670/71 at an m.o.i. of $1.0 \mathrm{PFU} /$ cell for $18 \mathrm{~h}$ or at an m.o.i. of $20 \mathrm{PFU} /$ cell for $7 \mathrm{~h}$, with or without 100 $\mu \mathrm{g} / \mathrm{ml}$ guanidine $\mathrm{HCl}$ (Gua, a picornavirus RNA synthesis inhibitor ${ }^{[22]}$ which strongly inhibits EV70 RNA synthesis at $100 \mu \mathrm{g} / \mathrm{ml}^{[12]}$ ) (Fig. 5B and 5D). Gua inhibited EV70 induced apoptotic DNA ladders of SRA01/04 cells in the above multiple-step viral growth experiment but not in the one-step viral growth experiment (Fig. 5B, lanes of Gua and EV70 + Gua) (Fig. 5B). In addition, APOPercentage dye uptake bioassay indicated that Gua inhibited $86.7 \%$ of EV70 induced apoptosis of SRA01/04 cells in the multiplestep viral growth experiment $(\mathrm{p}<<0.01)$ but not in the one-step viral growth experiment $(\mathrm{p}=0.5614)$ (Fig. 5D, lanes of Gua and EV70 + Gua). The results suggest that in SRA01/04 cells, EV70 induced apoptosis is not directly dependent on EV70 viral genome RNA synthesis. To determine whether the syntheses of EV70 viral proteins are involved in the process of EV70 induced apoptosis, SRA01/04 cells were infected with EV70 J670/71 at an m.o.i. of 1.0 PFU/cell for $18 \mathrm{~h}$ or at an m.o.i. of $20 \mathrm{PFU} /$ cell for $7 \mathrm{~h}$, with or without 2.5 $\mu \mathrm{g} / \mathrm{ml}$ cycloheximide (CHX, a protein synthesis inhibitor $^{[22]}$ which inhibits EV70 protein synthesis at
$2.5 \mu \mathrm{g} / \mathrm{ml}^{[12]}$ ) (Fig. 5C and 5D). CHX greatly reduced/inhibited EV70 induced apoptotic DNA ladders of SRA01/04 cells in the above multiple-step and one-step viral growth experiments (Fig. 5C, lanes of $\mathrm{CHX}$ and EV70 + CHX). APOPercentage dye uptake bioassay indicated that CHX significantly inhibited 98.3\% and $59.4 \%$ of EV70 induced apoptosis of SRA01/04 cells respectively, in both the multiple-step $(\mathrm{p}<<0.01)$ and the one-step viral growth experiment ( $\mathrm{p}$ $<<0.01$ ) (Fig. 5D, lanes of CHX and EV70 + CHX). The results suggest that in SRA01/04 cells, EV70 induced apoptosis is dependent on EV70 viral protein syntheses.

EV70 major capsid proteins do not appear involved in EV70 induced apoptosis of SRA01/04 cells: In the multiple-step virus growth experiment of Fig. 1C, EV70 progeny virus production and the expressions of the major capsid proteins had the following features: (a) the intracellular infectious EV70 (produced and retained within SRA01/04 cells) were sharply increased to near their maximum level between $3 \mathrm{~h}$ and $7 \mathrm{~h}$ p.i., increased very little between $7 \mathrm{~h}-13 \mathrm{~h}$ p.i and decreased thereafter (Fig. 6A, intracellular virus titer-time curve); (b) the infectious EV70 progeny viruses released to the extracellular DMEM medium sharply increased prior to $7 \mathrm{~h}$ p.i. and then gradually increased until $13 \mathrm{~h}$ p.i. (Fig. 6A, extracellular virus titer-time curve); (c) Western blotting with UV-inactivated anti-EV70 J670/71 


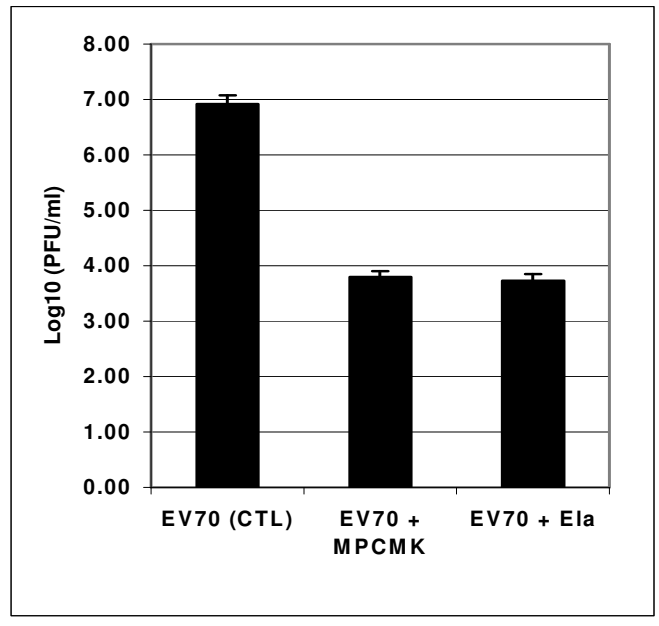

A

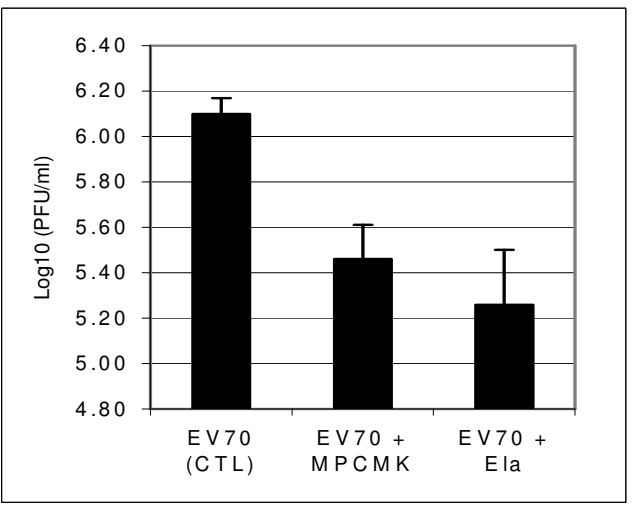

$\mathrm{C}$

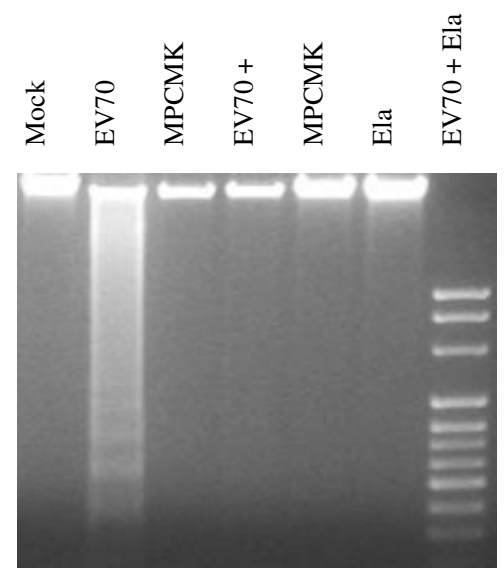

B

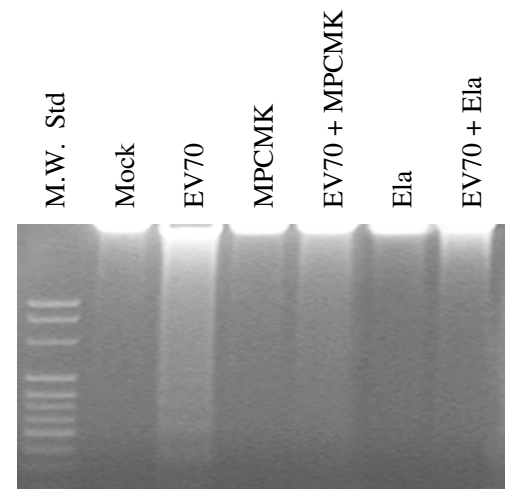

$\mathrm{D}$

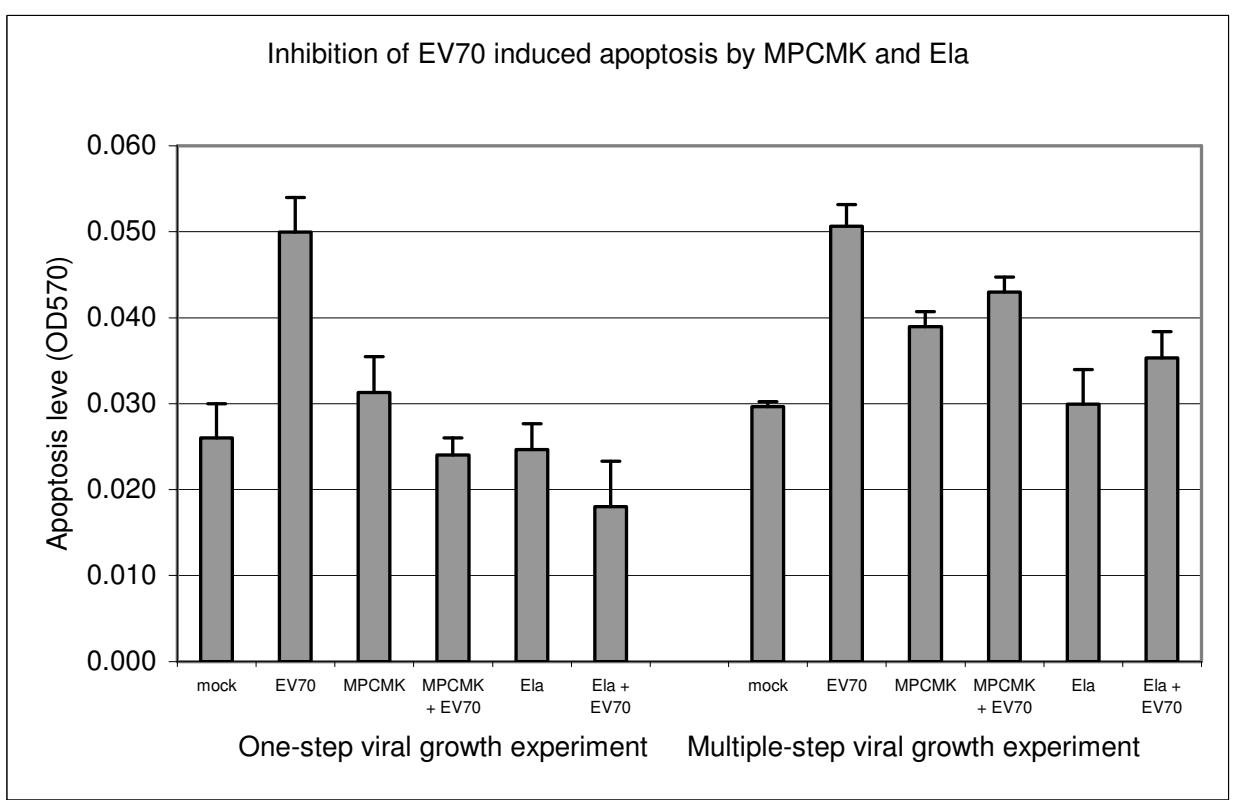

E

Fig. 7: Effects of MPCMK (methoxysuccinyl-Ala-Ala-Pro-Val-chloromethylketone) and Elastatinal (Ela) on EV70 J6 70/71 induced apoptosis. Virus titers (A and C) in media from virus-infected SRA01/04 cells with/without MPCMK $(0.5 \mathrm{mM})$ or Ela $(125 \mathrm{mM})$ in 6-well plates were quantitated while apoptosis levels in mock- and virus-infected SRA01/04 cells as well as SRA01/04 cells for the chemical controls in 6-well plates were analyzed by apoptotic DNA ladders (B and D), or apoptosis levels of similarly treated cells in 96-well plates were analyzed by APOPercentage dye uptake bioassay (E). M.W. Std. is the molecular standards. (A) MPCMK and Ela inhibited extracellular EV70 titer during multiple-step viral growth (1.0 PFU/cell, 18 h). (B) MPCMK and Ela inhibited EV70 induced apoptosis during multiple-step viral growth (1.0 PFU/cell, 18 h). (C) MPCMK and Ela inhibited extracellular EV70 titer during one-step viral growth (10 PFU/cell, 7 h). (D) MPCMK and Ela inhibited EV70 induced apoptosis during one-step viral growth (10 PFU/cell, 7 h). (E) Quantitation of EV70 induced apoptosis inhibited by MPCMK $(0.5 \mathrm{mM})$ and Ela $(125 \mathrm{mM})$. In one-step viral growth experiment (10 PFU/cell, $7 \mathrm{~h})$, MPCMK and Ela totally inhibited EV70 induced apoptosis $(\mathrm{p}<<0.01)$. In multiple-step viral growth experiment (1.0 PFU/cell, $18 \mathrm{~h})$, MPCMK and Ela significantly inhibited EV70 induced apoptosis by $83.6 \%(\mathrm{p}=0.009)$ and $78.1 \%(\mathrm{p}=0.002)$ respectively. Data shown in $(\mathrm{A}),(\mathrm{C})$ and $(\mathrm{E})$ are means \pm S.E. of 3 parallel experiments 
hyperimmune antiserum indicated that the intracellular levels of EV70 VP1 [the immunodominant capsid protein of $\left.\mathrm{EV} 0^{[3]}\right]$ within SRA01/04 cells sharply increased to near maximum between $3 \mathrm{~h}$ and $7 \mathrm{~h}$ p.i. but increased very little after $7 \mathrm{~h}$ p.i. (Fig. 6B). The intracellular EV70 VP2 and VP3 levels had similar change-patterns although the antiserum adopted was not as sensitive to VP2 and VP3 as to VP1 (Fig. 6B). In combination of Fig. 1C and Fig 6B, the expressions of EV70 major capsid proteins (VP1, VP2 and VP3) correlated with the changes in the intracellular virus titer but not the apoptotic DNA ladders. Therefore, the results suggest that EV70 major capsid proteins do not appear to be directly involved in EV70 induced apoptosis process of SRA01/04 cells.

EV70 2A protease is involved in the EV70 induction of apoptosis of SRA01/04 cells: Poliovirus 2A protease $^{[24,25]}$ and $3 \mathrm{C}$ protease ${ }^{[26 ; 27]}$ and EV71 2A protease $^{[28]}$ and $3 \mathrm{C}$ protease ${ }^{[29]}$ were reported to induce apoptosis of host cells. Elastatinal (Ela) and methoxysuccinyl-Ala-Ala-Pro-Val-chloromethylketone (MPCMK) are the currently available inhibitors for $2 \mathrm{~A}$ proteases of poliovirus and rhinovirus. To determine whether EV70 2A protease is directly involved in EV70 induced apoptosis, confluent SRA01/04 cells were infected with EV70 at an m.o.i. of 1.0 PFU/cell for $18 \mathrm{~h}$ (multiple-step viral growth), or at an m.o.i. of 10 PFU/cell for $7 \mathrm{~h}$ (one-step viral growth), with or without Ela $(125 \mathrm{mM})$ or MPCMK $(0.5 \mathrm{mM})$. In the above multiple-step viral growth experiment, Ela and MPCMK almost completely inhibited EV70 induced apoptotic DNA ladders of SRA01/04 cells while inhibiting about $99.9 \%$ of extracellular EV70 titer (Fig. $7 \mathrm{~A}$ and 7B). APOPercentage dye uptake bioassay indicated that Ela and MPCMK inhibited $78.1 \%$ and $83.6 \%$ respectively, of EV70 induced apoptosis of SRA01/04 cells in the multiple-step viral growth experiment ( $\mathrm{p}<<0.01)$ (Fig. 7E, lanes in "multiple-step viral growth experiment"). In the one-step viral growth experiment, Ela and MPCMK also significantly inhibited EV70 induced apoptosis of SRA01/04 cells, inhibiting about $74.4 \%$ and $84 \%$ respectively of extracellular EV70 titer (Fig. 7C and 7D). APOPercentage dye uptake bioassay indicated that Ela and MPCMK almost totally inhibited EV70 induced apoptosis of SRA01/04 cells in the one-step viral growth experiment ( $\mathrm{p}<0.01$ ) (Fig. 7E, lanes in "onestep viral growth experiment"). The results suggest that Ela and MPCMK at high concentrations inhibit EV70 induced apoptosis through inhibiting the activity of EV70 2A protease (and possibly $3 \mathrm{C}$ protease).

\section{DISCUSSION}

EV70 has a broader in vitro tropism than other human enterovirus ${ }^{[30]}$. EV70 induced apoptosis in both
HCC and SRA01/04 cells, may suggest that the virus may use apoptosis to damage not only human conjunctival and corneal cells (in AHC) but also other permissive human cells such as lens epithelial cells whenever these cells are accessible to this virus. Therefore, EV70 caused diseases may not be limited to $\mathrm{AHC}$ and its neurological complications.

EV70 induced apoptosis in SRA01/04 cells, like that in HCC cells ${ }^{[12]}$, is dose (m.o.i.)- and timedependent. In addition, the time required to induce apoptosis in both cells was inversely related to the EV70 multiplicity of infection (m.o.i.), i.e., the longer the infection time, the lower an m.o.i. required for the detection of a certain level of apoptosis induced by EV70. The apoptosis of SRA01/04 and HCC cells induced by EV70, suggests that (a) apoptosis is a major mechanism for the pathogenesis of EV70 because natural viral infection happens mostly at a low m.o.i. and (b) the mechanisms of EV70 induced apoptosis and/or necrosis (the latter occurs at high m.o.i.) may, through cell lysis ${ }^{[12]}$, help spread progeny viruses.

In one-step viral growth experiments, the infection of SRA01/04 cells with EV70 at a high m.o.i. resulted in faint smeared apoptotic DNA ladders, differing from the results with HCC cells (where the apoptotic DNA ladders were clear). This suggests that both apoptosis and necrosis occurred in human lens epithelial cells infected by EV70 at a high m.o.i., which is consistent with results from picornavirus coxsackievirus B5 $(\mathrm{CVB}-5)^{[31]}$, indicating that (a) in a virus infection, a low m.o.i. is likely to induce apoptosis while a high m.o.i. is likely to induce apoptosis plus necrosis and (b) different cells respond differently to a virus at a high m.o.i., especially in terms of necrosis. Therefore, the study of EV70 induced apoptosis of SRA01/04 cells may provide more information on the mechanisms for EV70 caused diseases.

EV70 induced apoptosis of SRA01/04 cells is dependent on the activation of caspase- 3 and 7 but not caspase-6, with caspase-3 being the major effector caspase. This is similar to EV70 induced apoptosis of HCC cells ${ }^{[12]}$, except some variation in changing patterns of the caspase- 6 activity and protein level between the two cell lines: when HCC or SRA01/04 cells were infected at 0.5 or $1.0 \mathrm{PFU} /$ cell for $3 \mathrm{~h}-18 \mathrm{~h}$, the enzymatic activity and protein level of caspase- 6 in HCC cells increased over the time of EV70 infection prior to $10 \mathrm{~h}$ p.i. and thereafter decreased while these in SRA01/04 cells did not increase over EV70 infection time course prior to $10 \mathrm{~h}$ p.i. but gradually decreased from $3 \mathrm{~h}$ to $18 \mathrm{~h}$ p.i. How this difference occurred in the two human eye cell lines should be studied in the future. Besides, pan-caspase inhibitor, caspase inhibitor IX (Z-VD-FMK), dose dependently and timesensitively inhibited EV70 induced apoptosis and caspase-3-like activity in both cell lines, suggesting that EV70 induced apoptosis is a caspase-dependent 
mechanism and mainly dependent on the activation of caspase-3 and caspase-7. In addition, like with HCC cells, EV70 induced apoptosis in SRA01/04 cells requires native (wild type) infectious virus since UVinactivated or heat-inactivated EV70 was not capable of inducing apoptosis. This suggests that it is unlikely for EV70 to trigger apoptosis of SRA01/04 cells by the interaction of just the viral capsid with host cell membrane or by virion uncoating found with Sindbis virus $^{[32]}$. Guanidine. $\mathrm{HCl}$ inhibited EV70 induced apoptosis of SRA01/04 cells in a multiple-step viral growth experiment but not in a one-step viral growth experiment, suggesting that (a) viral genome RNA synthesis is not directly required for EV70 induced apoptosis and (b) other products in EV70 replication are required for EV70 induced apoptosis. Low concentration $(2.5 \mu \mathrm{g} / \mathrm{ml})$ of cycloheximide inhibited EV70 induced apoptosis of SRA01/04 cells in both multiple-step and one-step viral growth experiments, strongly suggesting that a viral protein(s) synthesized during EV70 replication is/are required for EV70 induced apoptosis. It was reported that the major capsid proteins of some picornaviruses such as the VP1 of foot-and-mouth disease virus ${ }^{[33]}$, the VP2 of coxsackievirus $\mathrm{B} 3^{[34,35]}$ and the VP3 of avian encephalomyelitis virus ${ }^{[36]}$ were capable of inducing apoptosis. However, the expressions of EV70 major capsid proteins did not correlate with the apoptosis of SRA01/04 or HCC cells, leading us to believe that EV70 major capsid proteins are not directly involved in the apoptosis induction in both cell lines although this needs further support from future functional experiments. In addition, poliovirus $2 \mathrm{~A}$ protease $\mathrm{e}^{[37,38]}$ and $3 \mathrm{C}$ protease $\mathrm{e}^{[39,40]}$ and EV71 2A protease ${ }^{[41]}$ were reported to induce apoptosis of host cells. In our study, high concentrations of MPCMK and elastatinal (inhibitors of poliovirus or rhinovirus 2A protease) inhibited EV70 induced cell death of SRA01/04 cells by apoptosis, suggesting that EV70 2A protease protein produced during EV70 replication directly induces apoptosis of host cells. But this cannot exclude the involvement of EV70 3C protease during apoptosis induction because (a) some picornavirus protease inhibitors such as homophthalimides have dual inhibitive roles, i.e., inhibiting both $2 \mathrm{~A}$ and $3 \mathrm{C}$ proteases and (b) the concentrations of MPCMK and elastatinal (especially the latter) used was high and might inhibit both the 2 proteases. Therefore, we conclude that the mechanisms for EV70 induced apoptosis in both HCC cells and SRA01/04 cells are about the same or similar. Moreover, future directions involved EV70 should include (a) to determine whether EV70 can cause diseases other than AHC or its neurological complications; (b) to determine whether EV70 infection can induce the apoptosis of other permissive human cells such as monocytes and dendritic cells; and (c) to determine (using human cells such as HCC and SRA01/04 cells) the possible individual roles of EV70 $3 \mathrm{C}$ and $2 \mathrm{~A}$ proteases in the initiation process of EV70-induced apoptosis and how they might activate caspases, especially the effector caspases-3 and 7.

\section{ACKNOWLEDGEMENTS}

The authors thank Dr. Marguerite Yin-Murphy (Department of Microbiology, National University of Singapore, Singapore) for providing J670/71 EV70 epidemic isolate, Dr. Venkat N. Reddy (Department of Ophthalmology and Visual Sciences, Kellogg Eye Center, Uni. MI, Ann Arbor, MI) for gifting human lens epithelial SRA01/04 cells and Dr. Dennis O'Callaghan (Department of Microbiology and Immunology, LSU Health Sciences Center in Shreveport, LA) for generously providing access to his core facilities. This work was supported by the LSUHSC Eye Clinic and Department of Ophthalmology, LSU Health Sciences Center in Shreveport.

\section{REFERENCES}

1. Wright, P.W., G. H. Strauss and M. P. Langford, 1992. Acute hemorrhagic conjunctivitis. Am. Fam. Physician, 45: 173-178.

2. Wolken, S.H., 1974. Acute hemorrhagic conjunctivitis. Surv. Ophthalmol., 19: 71-84.

3. Chen, D., C. Duggan, J.P. Ganley, L.M. Kooragayala, T.B. Reden, D.E. Texada and M.P. Langford, 2004. Expression of enterovirus 70 capsid protein VP1 in Escherichia coli. Protein Expression and Purification, 37: 426-433.

4. Chen, D., C. Duggan, D.E. Texada, T.B. Reden, L.M. Kooragayala and M.P. Langford, 2005. Immunogenicity of enterovirus 70 capsid protein VP1 and its non-overlapping $\mathrm{N}$ - and C-Terminal fragments. Antiviral Research, 66: 111-117.

5. Hung, T.P., 1981. A polio-like syndrome in adults following acute hemorrhagic conjunctivitis. Int. J. Neurol., 15: 266-278.

6. Phuapradit, P., N. Roongwithu, P. Limsukon, P. Boongird and A. Vejjajiva, 1976. Radiculomyelitis complicating acute haemorrhagic conjunctivitis. A clinical study. J. Neurol. Sci., 27: 117-122.

7. Saenz, R.E., L. Castillo and E. Quiroz, 1984. Radiculomyelitis following acute hemorrhagic conjunctivitis caused by enterovirus 70 . Report of the 1 st corroborated case in America. Rev. Med. Panama, 9:176-181.

8. Sklar, V.E., P.A. Patriarca, I.M. Onorato, M.P. Langford, S.W. Clark, W.W. Culbertson and R.K. Forster, 1983. Clinical findings and results of treatment in an outbreak of acute hemorrhagic conjunctivitis in southern Florida. Am. J. Ophthalmol., 95: 45-54. 
9. Langford, M.P., M. Yin-Murphy, J.C. Barber, H.K. Heard and G.J. Stanton, 1986. Conjunctivitis in rabbits caused by enterovirus type 70 (EV70). Invest. Ophthalmol. Vis. Sci., 27: 915-920.

10. Haddad, A., M.R. Nokhbeh, D.A. Alexander, S.J. Dawe, C. Grise, N. Gulzar and K. Dimock, 2004. Binding to decay-accelerating factor is not required for infection of human leukocyte cell lines by enterovirus 70. J. Virol., 78: 2674-2681.

11. Chen, D., D.E. Texada, C. Duggan, Y. Deng and M.P. Langford, 2006. Caspase-3 and 7 mediates apoptosis of human conjunctival cells induced by enterovirus 70. Virology in press.

12. Langford, M.P., R. Orillac, D. Chen and D.E. Texada, 2003. Systemic and ocular antibody responses to inactivated acute hemorrhagic conjunctivitis (AHC) virus; enterovirus 70 (EV70). Ocular Immunol. Inflamm., 11: 197-209.

13. Langford, M.P. and G.J. Stanton, 1980. Replication of acute hemorrhagic conjunctivitis viruses in conjunctival-corneal cell cultures of mice, rabbits and monkeys. Invest. Ophthalmol. Vis. Sci., 19: 1477-1482.

14. Chen, D., C. Duggan, T.B. Reden, L.M. Kooragayala, D.E. Texada and M.P. Langford, 2004. Calreticulin is a binding protein for muramyl dipeptide and peptidoglycan in RK13 cells. Biochemistry, 43: 11796-11801.

15. Langford, M.P., R. Crainic, R. Vrijsen and E. Wimmer, 1991. Antibodies may act synergistically or additively with interferon to inhibit poliovirus. Microb. Pathog., 10: 419-427.

16. Chen, D., D.E. Texada, C. Duggan, C. Liang, B.R. Thomas, L.M. Kooragayala and M.P. Langford, 2005. Surface calreticulin mediates muramyl dipeptide-induced apoptosis. J. Biol. Chem., 280: 22425-22436.

17. Miyamura, K., S. Yamazaki, E. Tajiri and R. Kono, 1974. Growth characteristics of acute hemorrhagic conjunctivitis (AHC) virus in monkey kidney cells. I. Effect of temperature on viral growth. Intervirology, 4: 279-286.

18. Rasilainen, S., P. Ylipaasto, M. Roivainen, R. Lapatto, T. Hovi and T. Otonkoski, 2004. Mechanisms of coxsackievirus B5 mediated betacell death depend on the multiplicity of infection. J. Med. Virol., 72: 586-596.

19. Calandria, C., A. Irurzun, A. Barco and L. Carrasco, 2004. Individual expression of poliovirus 2Apro and 3Cpro induces activation of caspase-3 and PARP cleavage in HeLa cells. Virus Res., 104: 39-49.

20. Goldstaub, D., A. Gradi, Z. Bercovitch, Z. Grosmann, Y. Nophar, S. Luria, N. Sonenberg and C. Kahana, 2000. Poliovirus 2A protease induces apoptotic cell death. Mol. Cell Biol., 20: 1271-1277.
21. Barco, A., E. Feduchi and L. Carrasco, 2000. Poliovirus protease $3 \mathrm{C}$ (pro) kills cells by apoptosis. Virology, 266: 352-360.

22. Kuo, R.L., S.H. Kung, Y.Y. Hsu and W.T. Liu, 2002. Infection with enterovirus 71 or expression of its 2A protease induces apoptotic cell death. J. Gen. Virol., 83: 1367-1376.

23. Li, M.L., T.A. Hsu, T.C. Chen, S.C. Chang, J.C. Lee, C.C. Chen, V. Stollarand S.R. Shih, 2002. The $3 \mathrm{C}$ protease activity of enterovirus 71 induces human neural cell apoptosis. Virology, 293: 386395.

24. Jan, J.T., S. Chatterjee and D.E. Griffin, 2000. Sindbis virus entry into cells triggers apoptosis by activating sphingomyelinase, leading to the release of ceramide. J. Virol., 74: 6425-6432.

25. Peng, J.M., S.M. Liang and C.M. Liang, 2004. VP1 of foot-and-mouth disease virus induces apoptosis via the Akt signaling pathway. J. Biol. Chem., 279: 52168-52174.

26. Henke, A., H. Launhardt, K. Klement, A. Stelzner, R. Zell and T. Munder, 2000. Apoptosis in coxsackievirus B3-caused diseases: interaction between the capsid protein VP2 and the proapoptotic protein siva. J. Virol., 74: 284-4290.

27. Henke, A., M. Nestler, S. Strunze, H. P. Saluz, P. Hortschansky, B. Menzel, U. Martin, R. Zell, A. Stelzner and T. Munder, 2001. The apoptotic capability of coxsackievirus B3 is influenced by the efficient interaction between the capsid protein VP2 and the proapoptotic host protein Siva. Virology, 289: 15-22.

28. Liu, J., T. Wei and J. Kwang, 2002. Avian encephalomyelitis virus induces apoptosis via major structural protein VP3. Virology, 300: 39-49.

29. Li, M.L., T.A. Hsu, T.C. Chen, S.C. Chang, J.C. Lee, C.C. Chen, V. Stollar and S.R. Shih, 2002. The $3 \mathrm{C}$ protease activity of enterovirus 71 induces human neural cell apoptosis. Virology, 293: 386395.

30. Haddad, A., M.R. Nokhbeh, D.A. Alexander, S.J. Dawe, C. Grise, N. Gulzar and K. Dimock, 2004. Binding to decay-accelerating factor is not required for infection of human leukocyte cell lines by enterovirus 70. J. Virol., 78: 2674-2681.

31. Rasilainen, S., P. Ylipaasto, M. Roivainen, R. Lapatto, T. Hovi and T. Otonkoski, 2004. Mechanisms of coxsackievirus B5 mediated betacell death depend on the multiplicity of infection. J. Med. Virol., 72: 586-596.

32. Jan, J.T., S. Chatterjee and D.E. Griffin, 2000. Sindbis virus entry into cells triggers apoptosis by activating sphingomyelinase, leading to the release of ceramide. J. Virol., 74: 6425-6432.

33. Peng, J.M., S.M. Liang and C.M. Liang, 2004. VP1 of foot-and-mouth disease virus induces apoptosis via the Akt signaling pathway. J. Biol. Chem., 279: 52168-52174. 
34. Henke, A., H. Launhardt, K. Klement, A. Stelzner, R. Zell and T. Munder, 2000. Apoptosis in coxsackievirus B3-caused diseases: interaction between the capsid protein VP2 and the proapoptotic protein siva. J. Virol., 74: 4284-4290.

35. Henke, A., M. Nestler, S. Strunze, H.P. Saluz, P. Hortschansky, B. Menzel, U. Martin, R. Zell, A. Stelzner and T. Munder, 2001. The apoptotic capability of coxsackievirus B3 is influenced by the efficient interaction between the capsid protein VP2 and the proapoptotic host protein Siva. Virology, 289: 15-22.

36. Liu, J., T. Wei and J. Kwang, 2002. Avian encephalomyelitis virus induces apoptosis via major structural protein VP3. Virology, 300: 39-49.

37. Calandria, C., A. Irurzun, A. Barco and L. Carrasco, 2004. Individual expression of poliovirus 2Apro and 3Cpro induces activation of caspase-3 and PARP cleavage in HeLa cells. Virus Res., 104: 39-49.
38. Goldstaub, D., A. Gradi, Z. Bercovitch, Z. Grosmann, Y. Nophar, S. Luria, N. Sonenberg and C. Kahana, 2000. Poliovirus 2A protease induces apoptotic cell death. Mol. Cell Biol., 20: 12711277.

39. Barco, A., E. Feduchi and L. Carrasco, 2000. Poliovirus protease $3 \mathrm{C}$ (pro) kills cells by apoptosis. Virology, 266: 352-360.

40. Calandria, C., A. Irurzun, A. Barco and L. Carrasco, 2004. Individual expression of poliovirus 2Apro and 3Cpro induces activation of caspase-3 and PARP cleavage in HeLa cells. Virus Res., 104: 39-49.

41. Kuo, R.L., S.H. Kung, Y.Y. Hsu and W.T. Liu, 2002. Infection with enterovirus 71 or expression of its $2 \mathrm{~A}$ protease induces apoptotic cell death. J. Gen. Virol., 83: 1367-1376. 